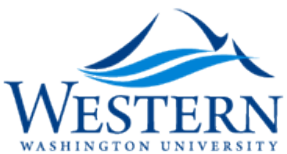

Western Washington University Western CEDAR

Spring 2019

\title{
Seismic Structure of Tanaga Island, Alaska
}

Kevin F. (Kevin Francis) Lally

Western Washington University, kevinfrancislally@gmail.com

Follow this and additional works at: https://cedar.wwu.edu/wwuet

Part of the Geology Commons

\section{Recommended Citation}

Lally, Kevin F. (Kevin Francis), "Seismic Structure of Tanaga Island, Alaska" (2019). WWU Graduate School Collection. 860. https://cedar.wwu.edu/wwuet/860

This Masters Thesis is brought to you for free and open access by the WWU Graduate and Undergraduate Scholarship at Western CEDAR. It has been accepted for inclusion in WWU Graduate School Collection by an authorized administrator of Western CEDAR. For more information, please contact westerncedar@wwu.edu. 


\section{Seismic Structure of Tanaga Island, Alaska}

By

Kevin Lally

Accepted in Partial Completion of the Requirements for the Degree Master of Science

\section{ADVISORY COMMITTEE}

Chair, Dr. Jackie Caplan-Auerbach

Dr. Bernard Housen

Dr. Pete Stelling

Dr. John Power

GRADUATE SCHOOL

Kathleen L. Kitto, Acting Dean 


\section{Master's Thesis}

In presenting this thesis in partial fulfillment of the requirements for a master's degree at Western Washington University, I grant to Western Washington University the nonexclusive royalty-free right to archive, reproduce, distribute, and display the thesis in any and all forms, including electronic format, via any digital library mechanisms maintained by WWU.

I represent and warrant this is my original work, and does not infringe or violate any rights of others. I warrant that I have obtained written permissions from the owner of any third party copyrighted material included in these files.

I acknowledge that I retain ownership rights to the copyright of this work, including but not limited to the right to use all or part of this work in future works, such as articles or books.

Library users are granted permission for individual, research and non-commercial reproduction of this work for educational purposes only. Any further digital posting of this document requires specific permission from the author.

Any copying or publication of this thesis for commercial purposes, or for financial gain, is not allowed without my written permission

Kevin Lally

May 22, 2019 


\title{
Seismic Structure of Tanaga Island, Alaska
}

\author{
A Thesis \\ Presented to \\ The Faculty of \\ Western Washington University
}

In Partial Fulfillment

Of the Requirements for the Degree

Master of Science

by

Kevin Lally

May 2019 
Abstract:

Tanaga Island is located in the Central Aleutian Islands and includes four stratovolcanoes: Sajaka, Tanaga, and East Tanaga in the northwest, and Takawangha in the central part of the island. Of these volcanoes, only Tanaga has a record of historical eruptive activity (in 1914). Over 3,000 earthquakes have been recorded beneath the island and the surrounding offshore region since the six-station seismic network was emplaced in 2003 . The origin of these earthquakes is not completely understood, and to arrive at this understanding, more accurate hypocenter locations and power spectra need to be determined. A better analyses including improved locations of earthquake hypocenters can provide useful constraints on volcanic and tectonic activity in the region. We use cross-correlation and double-difference methods to relocate Tanaga Island earthquakes from the period 2003-2017. High precision relative relocations show multiple subsurface faults in the Tanaga region related to volcanism and crustal tectonics. In 2005, a large volcanic swarm of nearly 600 volcano-tectonic (VT) events located below the NW portion of the island culminated with a several minute long episode of volcanic tremor. Although there was no verified eruption associated with this swarm, we suggest that this activity is associated with Takawangha volcano due to the shallowing of events towards Takawangha and the inferred location of the tremor signal. In 2008, a M6.6 earthquake was recorded $2.5 \mathrm{~km}$ east of Tanaga Island, associated with bookshelf faulting and the northwest translation of the Andreanof region. Shortly after the M6.6 event, two regions on Tanaga Island, 20 and $30 \mathrm{~km}$ west of the epicenter became seismically active, suggesting triggering by the M6.6. We also examine a variety of smaller swarms in the Tanaga area. From 2006-2017, we identify activity accommodating the clock-wise rotation of the Delarof Block (Geist et al., 1988), one of five forearc crustal blocks, including a small swarm in 2010. In 2006 heightened seismicity suggests brittle rupture possibly accompanied by fluid movement inferred from the observations of hybrid events $4 \mathrm{~km}$ south of Takawangha. In addition, shallow zones of 
brittle rupture were discovered $8 \mathrm{~km}$ south and $25 \mathrm{~km}$ southeast of Takawangha. This analysis suggests a complex pattern of earthquake hypocenters that is governed by both volcanic and tectonic processes surrounding Tanaga and Takawangha Volcanoes. 


\section{Table of Contents:}

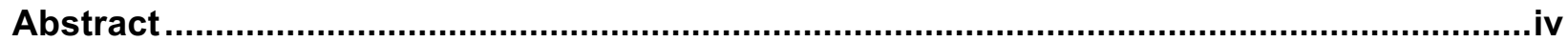

List of Figures and Tables ............................................................................................

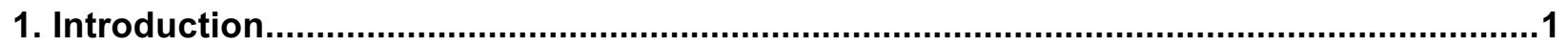

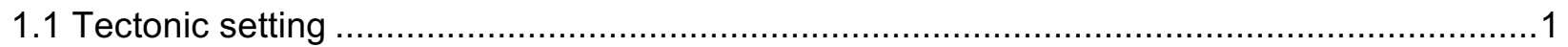

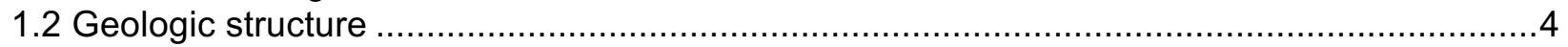

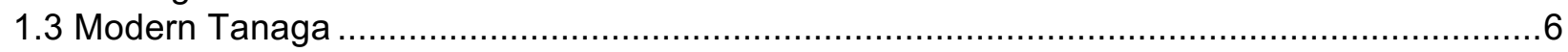

2. Methods

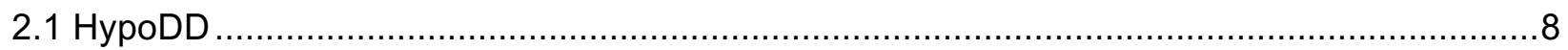

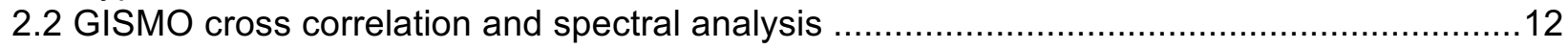

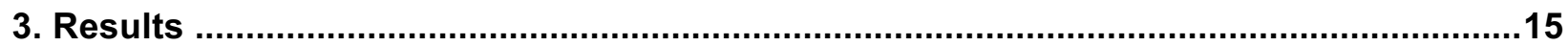

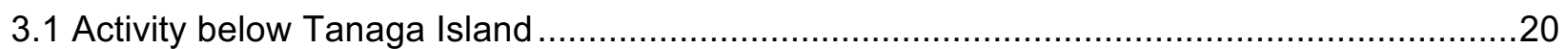

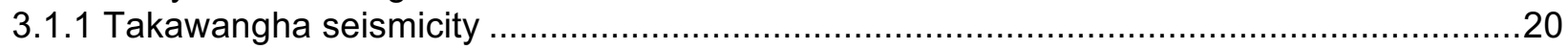

3.1.2 Seismicity below WTVC (Tanaga, East Tanaga, and Sajaka) ……............................28

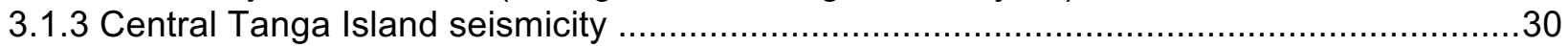

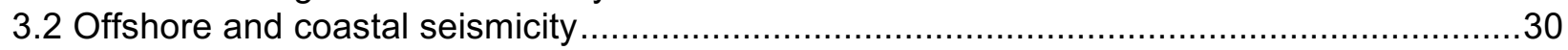

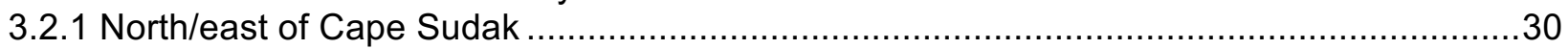

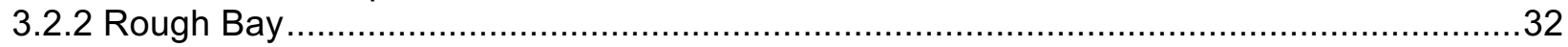

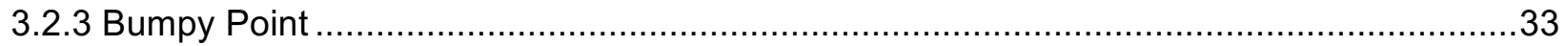

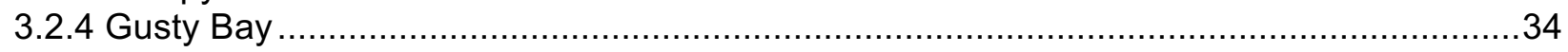

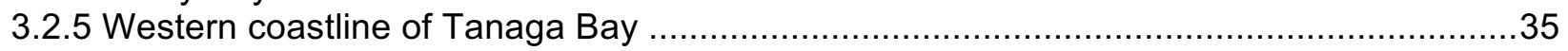

3.2.6 South Tanaga Island near the northern boundary of the Delarof block .............................36

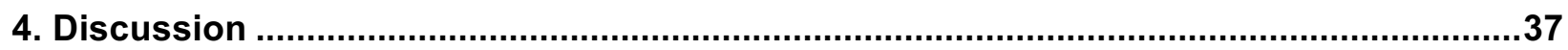

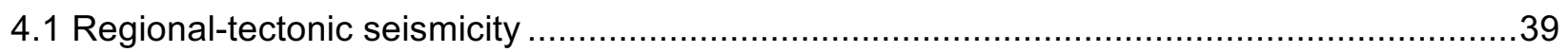

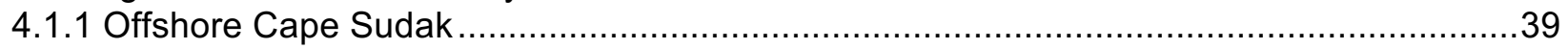

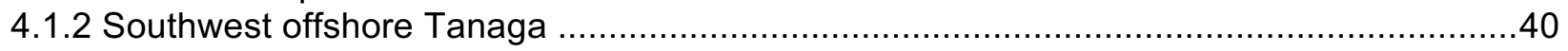

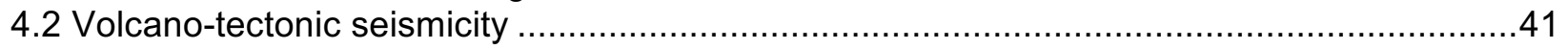

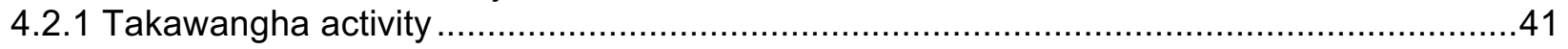

4.2.2 WTVC activity (Tanaga, East Tanaga, and Sajaka) .................................................. 47

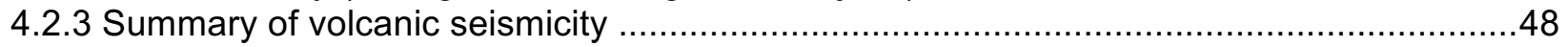

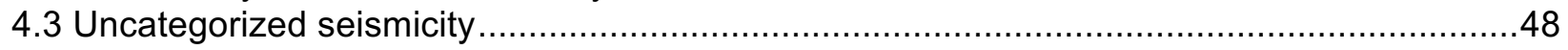

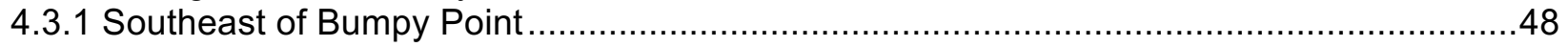

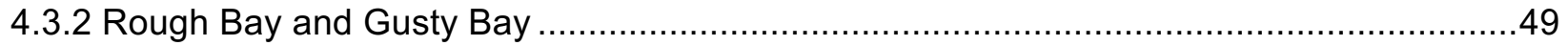

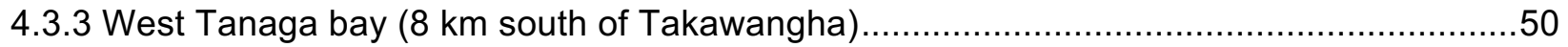

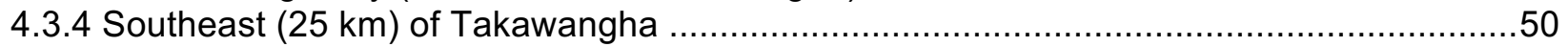

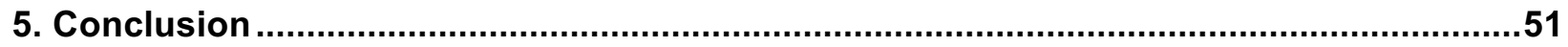

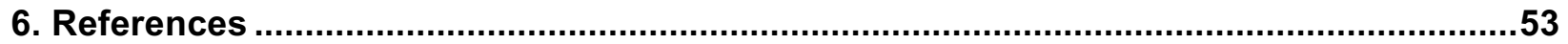

7. Appendix

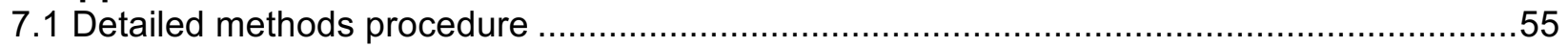

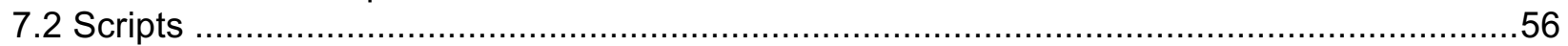

7.2.1 Python script (match-pha-timestamp-to-waveform-directory.py) created by Jim Long ......56

7.2.2 MATLAB script (SAC_add_pick_crscrl.m) created by Dr. Jackie Caplan-Auerbach ...........58

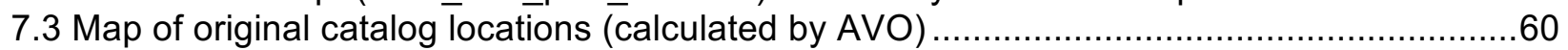

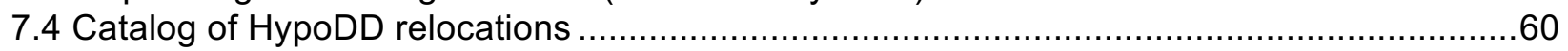




\section{List of Figures and Tables:}

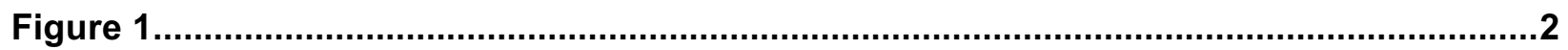

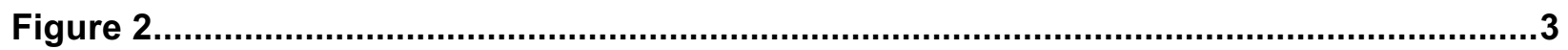

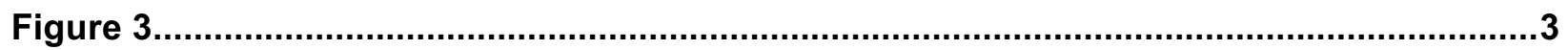

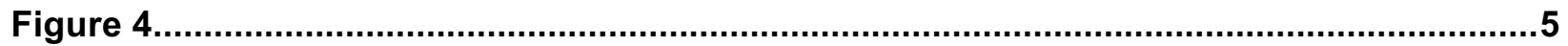

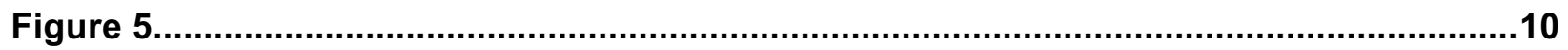

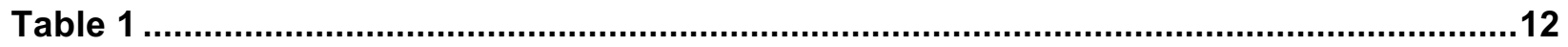

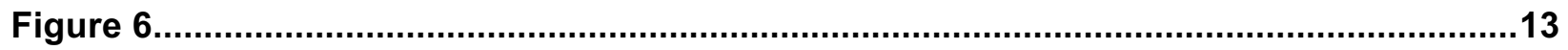

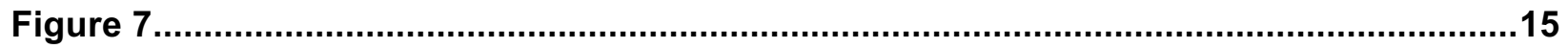

Figure 8

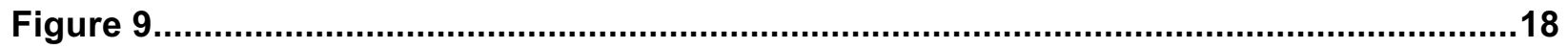

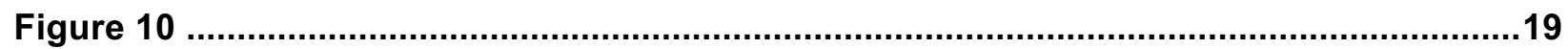

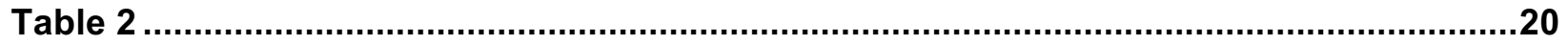

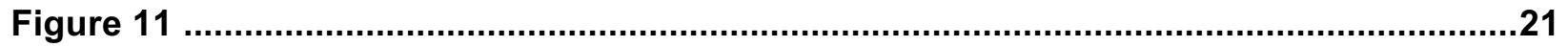

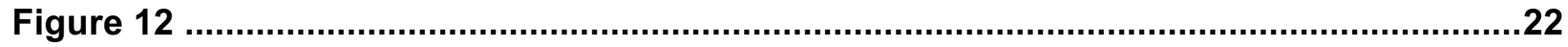

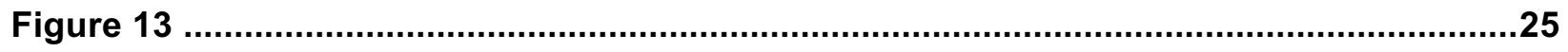

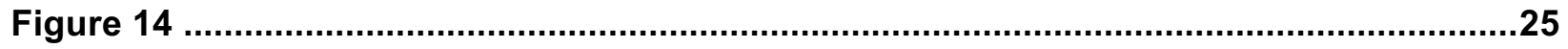

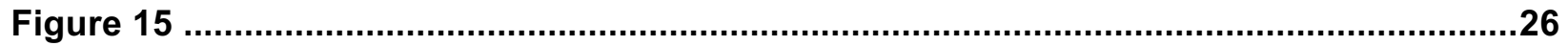

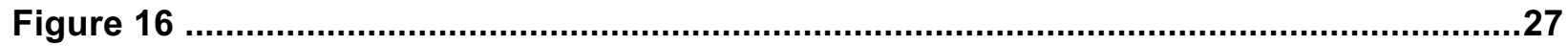

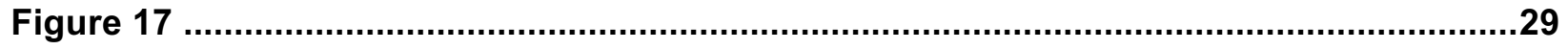

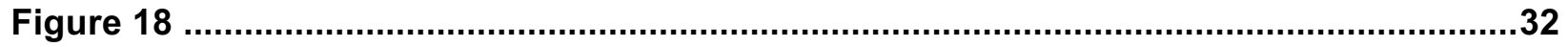

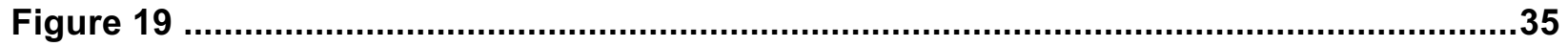

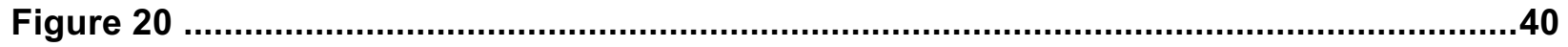

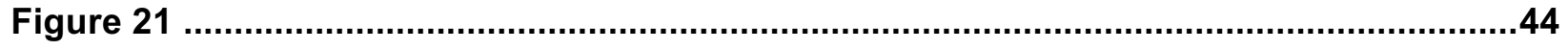

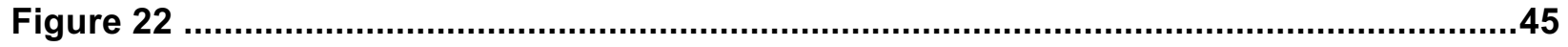

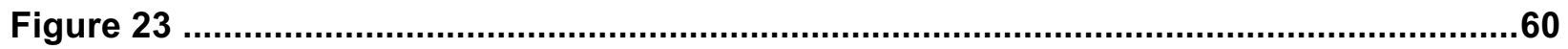


1. Introduction:

Seismicity in volcanic arcs may be generated by a variety of source processes:

volcanism, deformation of the subducting plate beneath the arc, or deformation of the arc crust. It is important to distinguish between these sources to know if seismicity represents a volcanic hazard or tectonic activity. Monitoring volcano seismicity is critical for understanding active magmatic systems, eruptive dynamics, and hazard assessment. For this study we used methods to relocate earthquakes nearby Tanaga Island in the western Aleutians, Alaska (Figure 1) with the goal of identifying seismic sources and subsurface structures. By examining the seismicity in the region, we explore the relationship between volcanism, subduction, and crustal block tectonics in the Tanaga area.

\subsection{Tectonic Setting}

The Aleutian Arc consists of about 25 volcanic islands and hundreds of islets. The arc results from subduction of the Pacific Plate beneath the overriding North American Plate. The relative angle of convergence along the Aleutian Arc decreases gradually westward, from normal convergence in the east to nearly pure dextral strike-slip motion in the west (Mortera-Gutierrez et al., 2003). Tanaga Island is located within the western Andreanof Islands where the relative convergence rate is $7.3 \mathrm{~cm} / \mathrm{yr}$ (Cross and Freymueller, 2007) and the Pacific Plate's motion direction is 319 degrees, which is oblique by 52 degrees relative to the trench azimuth (Mortera-Gutierrez et al., 2003). The island includes a system of four stratovolcanoes; three volcanoes (Tanaga, Sajaka, and East Tanaga) grouped in proximity on the northwest coast, and one larger isolated volcano (Takawangha) located $10 \mathrm{~km}$ southeast of the other cluster (Figure 1). 


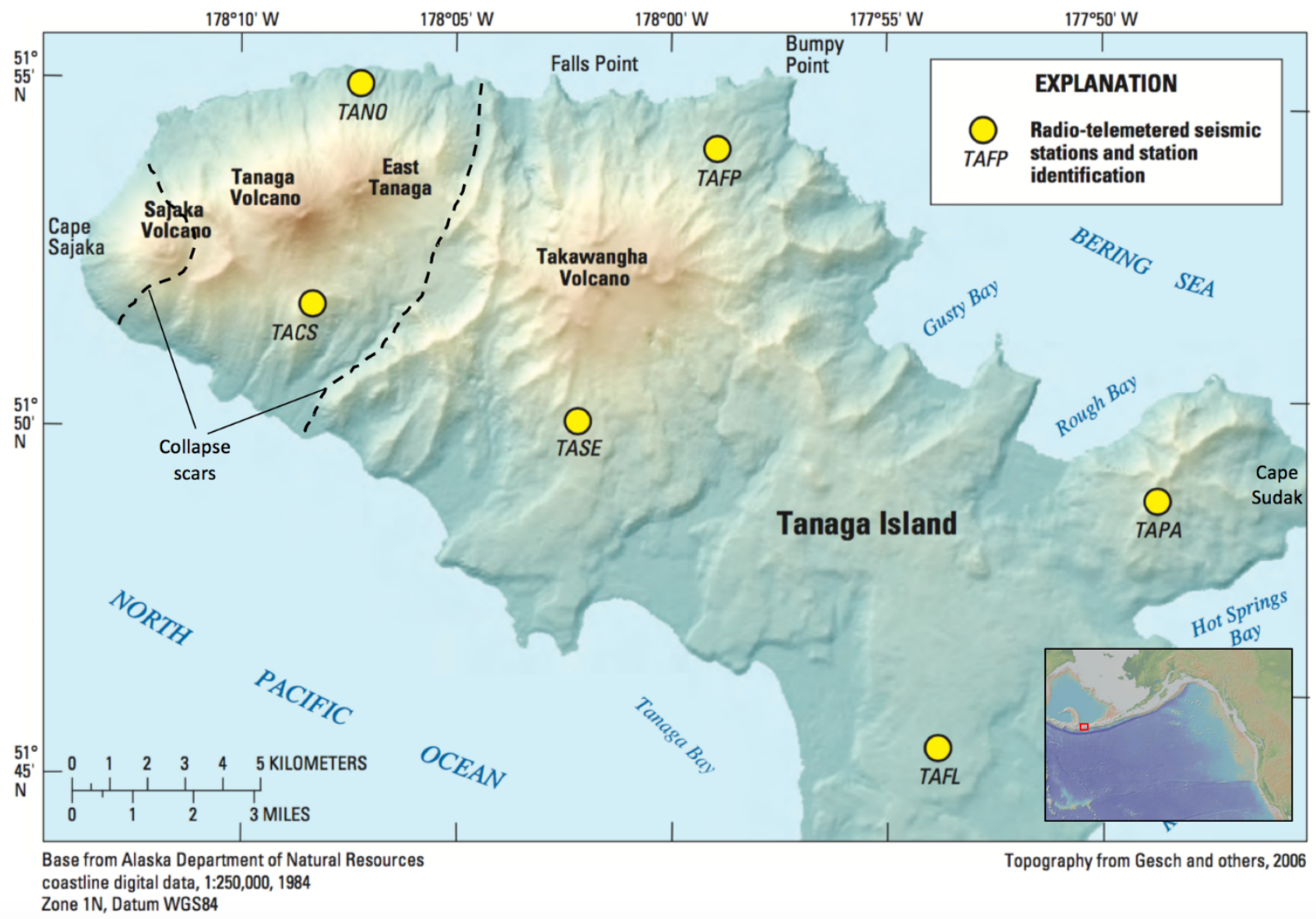

Figure 1: Map of Tanaga Island, Western Aleutians - courtesy of Coombs et al., 2007a. Yellow circles are the 6 seismic stations emplaced by Alaska Volcano Observatory (AVO) in 2003. Volcanic centers and coastal geographical names are labeled. Collapse scars are shown as dashed lines. In addition to the 6 seismometers on Tanaga island, another 11 seismometers are located on the 3 adjacent islands (see figure 3). (Figure modified from Coombs et al.,

The oblique convergence angle and regional plate coupling between the Pacific and North American Plates near the Andreanof Islands results in the northwestward transport of $>1$ $\mathrm{cm} / \mathrm{yr}$ (relative to North America) of the western Andreanof region (Cross and Freymueller, 2007). This phenomenon also causes portions of the forearc to deform as rotating, fault-bound blocks; Geist et al. (1988) suggests a model of five forearc crustal blocks in the central and eastern Aleutians. (Figure 2). The clock-wise rotation of crustal blocks in the forearc is responsible for a portion of the local stress orientations and many large magnitude strike-slip earthquakes (Figure 3; Ruppert et al., 2012). 


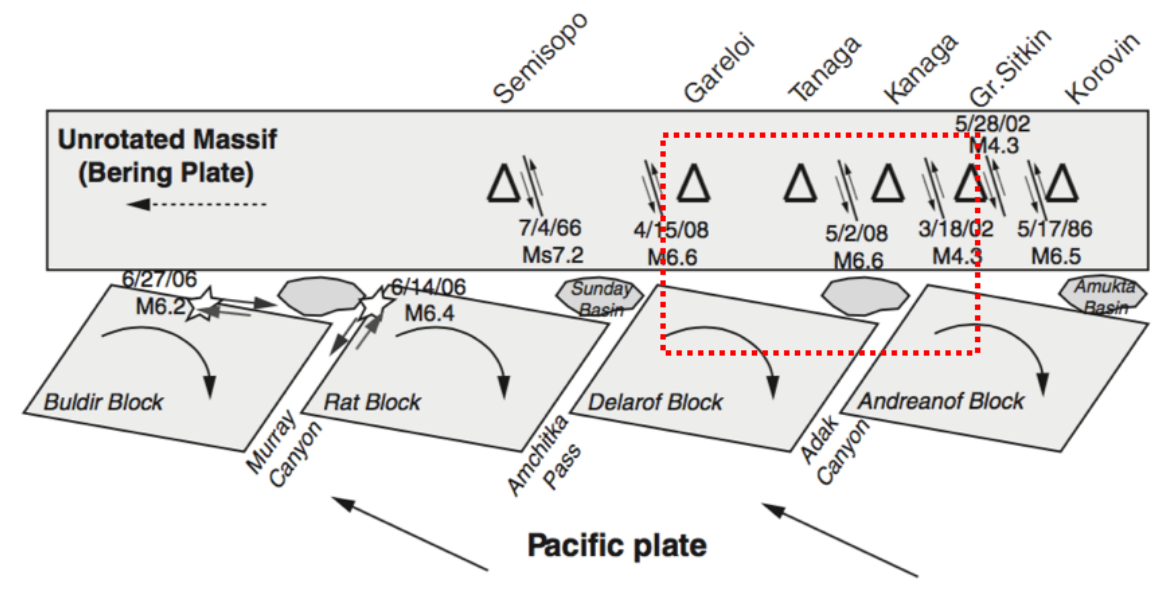

Figure 2: Illustration (not to scale) of the Central and Western Aleutian Arc depicting the fore-arc crustal block rotation caused by the oblique subduction of the Pacific plate.

Tanaga Island lies just north of the Delarof Block on the non-rotating massif of the Bering Plate. Between Tanaga and Kanaga Islands is the epicenter of the May 2, 2008 magnitude 6.6 earthquake which took place on a left lateral strike-slip fault. The location of Figure 3 is represented by the dotted red line. (Figure modified from Ruppert et al., 2012).

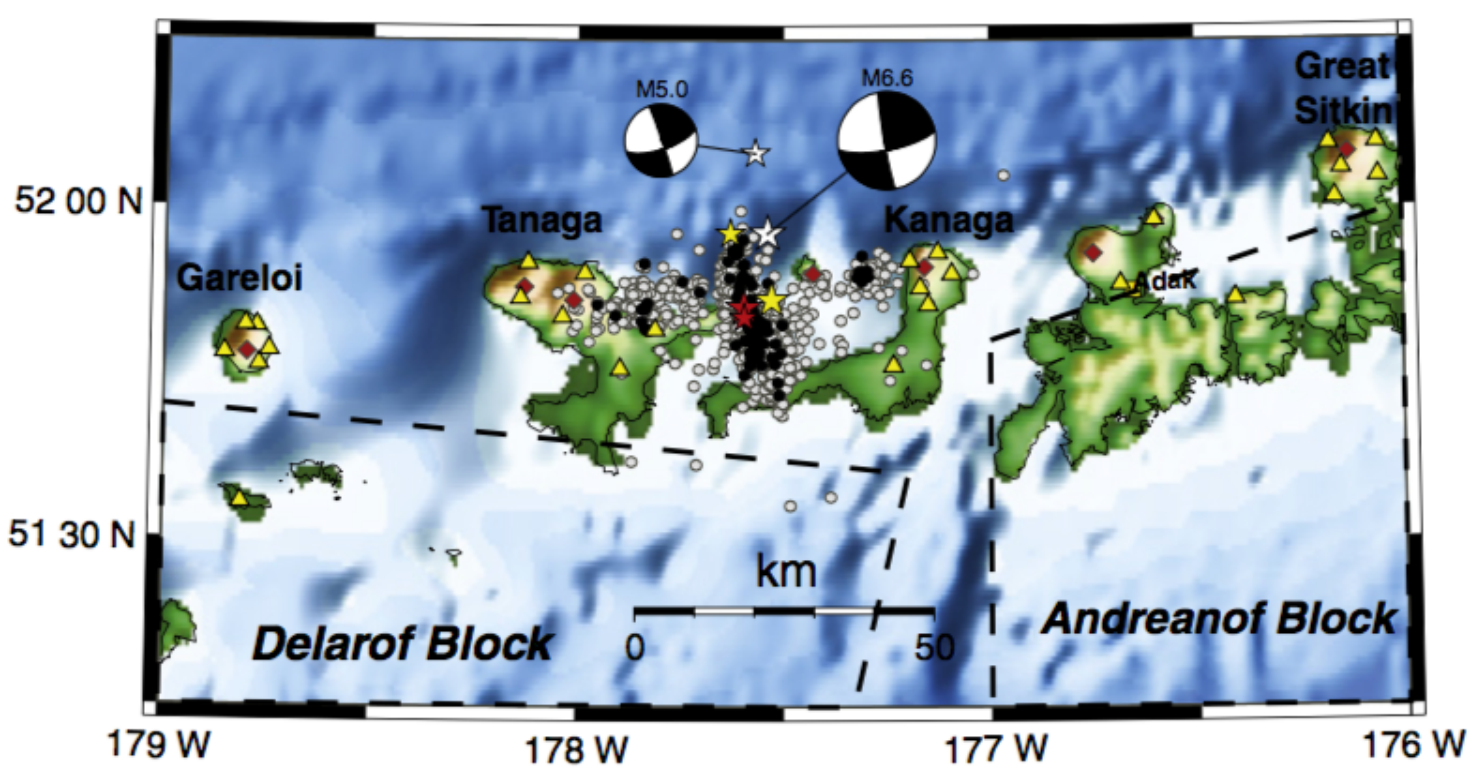

Figure 3: Location map showing the epicenters of the May 2008 mainshock-aftershock sequence. Red diamonds are volcanic centers. Yellow triangles are seismometer locations. White stars are Global CMT locations. Yellow stars are those same events relocated by Ruppert et al. (2012), and red stars are double-difference relocations (performed by Ruppert et al. (2012)) of the largest aftershocks. Black dots are magnitude $>2.5$ relocated events. Gray dots are original Alaska Earthquake Information Center catalog aftershock locations. Crustal fore-arc blocks designated by Geist et al., are outlined in dashed lines. (Figure from Ruppert et al., 2012) 


\subsection{Geologic Structure}

The volcanic history of Tanaga Island dates back to roughly $250 \mathrm{ka}$ and the volcanoes of the island have been periodically active since (Coats and Marsh, 1984). All four volcanic centers erupt basalt to basaltic andesite lava, and have produced lava flows and/or tephra deposits in the last 1,000 years, which by definition deems all four volcanoes active. Although there have been no known historical eruptions of either Takawangha or Sajaka, periodic "smoke" was reported in 1791 and 1829 above the island and the last recorded eruption of Tanaga was in 1914 which produced a blocky lava flow (Coats, 1950). Based on detailed geologic mapping and ${ }^{40} \mathrm{Ar} /{ }^{39} \mathrm{Ar}$ dating, Jicha et al. (2012) concluded that the focus of magmatic activity shifted away from Takawangha to Tanaga and Sajaka about $19 \mathrm{ka}$. In our discussion, we refer to the Tanaga Volcanic Cluster (TVC) as all four volcanic centers on Tanaga Island, and the Western Tanaga Volcanic Cluster (WTVC) as Tanaga, East Tanaga, and Sajaka. The TVC is unique in comparison to other volcanic islands in the Central Aleutians as Tanaga includes four volcanoes in proximity and may share a common parent magma (Jicha et al., 2012).

Tanaga Island is believed to have been a singular stratovolcano, ancestral Tanaga, which experienced two major edifice collapses into the sea (Coombs et al., 2007b), creating the configuration of the volcanic edifices seen today (Figure 4). Evidence of the first collapse (240$140 \mathrm{ka}$ ) formed when the northwest portion of ancestral Tanaga collapsed into the sea and is preserved as a broad crescent-shaped amphitheater scarp, concave to the west, separating Tanaga and Takawangha (Figure 1; Coombs et al., 2007b). The proposed surficial scar lies at the base of this prominent ridge and bathymetric maps confirm that it continues both to the north and south below sea-level (Coombs et al., 2007b). Jicha et al. (2012) report that the rocks along the steep scarp are highly hydrothermally altered $3 \mathrm{~km}$ due east of Takawangha and note the presence of possible conduit breccias, suggesting that the exposure is likely the remnant of 
ancestral Tanaga's volcanic center. The second edifice collapse occurred about $3 \mathrm{ka}$ on the west flank of Sajaka. A younger cone, known as Sajaka Two, grew in the resulting chasm (Figure 3; Coombs et al., 2007b).
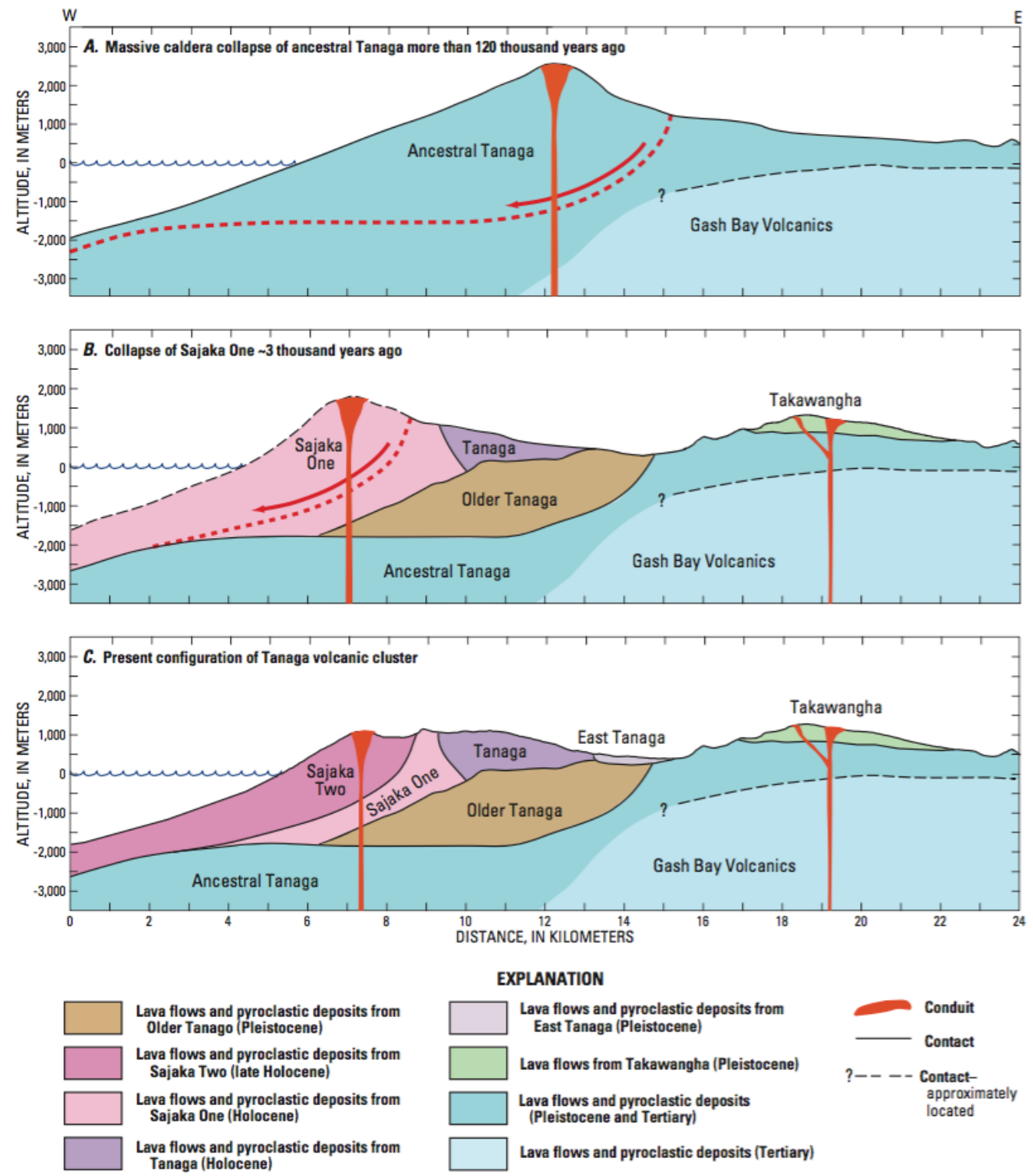

Figure 4: Cross-section view of Tanaga Island at 3 different points in time. The top figure, A, shows the first major edifice collapse occurring about 120,000 years ago. The middle figure, $B$, shows the second (and most recent) edifice collapse about 3,000 years ago. The bottom figure, $\mathrm{C}$, shows the current configuration of Tanaga Island. Note that due to where the cross-section line was chosen, the true peaks of Tanaga and East Tanaga are not shown. (Figure from Coombs et al., 2007b) 


\subsection{Modern Tanaga}

In August of 2003, the Alaskan Volcano Observatory (AVO) installed a sub-network of six seismometers (five single-component short-period seismometers and one three-component short-period seismometer) to monitor Tanaga Island. In addition to this local network, another 12 seismic stations are located on the two neighboring Islands (Kanaga and Gareloi). Earthquakes occur beneath Tanaga Island on a nearly daily basis, with over 3000 earthquakes recorded since the seismic network was installed, an average of 0.65 events per day, with occasional swarms of $>150$ events per day. Since 2003 , seismicity has occurred beneath all four volcanic centers, the amphitheater ridge, the central portion of the island and many offshore locations. Much of the offshore seismicity occurred as earthquake swarms or mainshockaftershock sequences near Bumpy Point, Rough Bay, Gusty Bay, Cape Sudak, and Tanaga Bay. The majority of seismicity which occurred beneath the volcanic centers took place during a swarm in October 2005. In addition, an episode of volcanic tremor was also observed during this time. The recent seismicity, between 2003-2017, below and offshore Tanaga Island demonstrates the importance of understanding and distinguishing between tectonic and volcanic sources.

Prior to this study, only catalog locations, hypocenters based on an analyst's identification of $\mathrm{P}$ and S-wave arrivals, had been determined for Tanaga area earthquakes. Initial AVO catalog locations were calculated with Hypoellipse between 2003-2012 (Lahr, 1999) and Hypoinverse between 2012-2017 (Klein, 2002) using a 1D velocity model (Dixon et al., 2012). These locations have varying accuracy due to event-to-event variability in signal-tonoise ratios. Such errors can create location uncertainties of more than a kilometer (Dixon et al., 2004; Dixon et al., 2006), making it difficult to resolve subsurface structures. The data set used in this study was provided by AVO and includes a list of catalog earthquake locations, analyst-identified P and S-wave travel times (at available stations), the errors and weights 
associated with each measurement, magnitudes determined using frequency amplitude measurements, waveform data, and seismometer station locations.

A major goal of this study is to identify the source mechanisms for Tanaga earthquakes as they may be caused by tectonics or volcanism. We use double-difference earthquake relocation to examine the high-resolution spatial relationships of the hypocenters.

Understanding this seismicity can provide insight into crustal fault structures, potential magmatic movement at depth, and which of the four volcanoes on Tanaga Island are seismically active and may pose an eruptive risk.

A second objective of the project is to classify earthquakes based on their spectral content and assumed source processes. Categorizing the earthquakes by both location and frequency allows us to resolve zones of brittle failure (producing high frequency earthquakes), zones generating activity due to subsurface fluid flow (long period earthquakes), and tectonic events related to the subduction of the Pacific plate or crustal block rotation (Chouet, 2003; McNutt, 2005). Another critical question we investigate is whether the 2005 seismic swarm was related to shallow magma injection as suggested by Lu and Dzurisin (2014). The goals of this project can be tested by precise relocation of hypocenters and investigating waveform spectral content. This classification provides greater insight into the governing forces acting locally to the Tanaga volcanic system: volcanic, subduction, and/or crustal block rotation.

\section{Methodology:}

In this study, we used high resolution relocation methods to identify the relative source location of each earthquake and minimize location uncertainties. Our dataset was limited to latitudes between 51.5 and 52 degrees North and longitudes between -177.5 and -178.5 degrees; this includes events offshore of Tanaga Island, but does not include events thought to 
be associated with neighboring volcanoes, Kanaga or Gareloi. Prior to relocating Tanaga events, data formats had to be made uniform due to the multiple formats received from AVO (waveform data in SAC and Mini-Seed and phase information in Hypoellipse (Lahr, 1999) and Hypoinverse (Klein, 2002)). In order to prepare the data for relocation, we cross-correlated all available Tanaga waveform files using the Waveform Cross Correlation Package created by Dr. Zhigang Peng (http://geophysics.eas.gatech.edu/people/zpeng/Software/sac_wfcc.tar.gz).

Both cross correlated and catalog travel times were used as inputs for the double difference algorithm, HypoDD (Waldhauser and Ellsworth, 2000), to determine more precise relative relocations. Events were also cross correlated using the GISMO toolbox in MATLAB (Reyes and West, 2011) to identify clusters of similar events. Swarm clusters were then stacked, and categorized by the spectral frequencies observed within event waveforms.

\subsection{HypoDD}

High-resolution earthquake relocations were calculated using the double-difference algorithm, HypoDD (Waldhauser and Ellsworth, 2000). HypoDD uses both catalog phase picks and adjusted arrival time picks after cross-correlation to relocate earthquake hypocenters relative to one another. Catalog and cross-correlated phase picks were used to relocate most individual earthquake swarms, however we were unable to determine cross-correlated times for the complete data set.

Prior to input into HypoDD, differential travel times were calculated for event pairs using the program Ph2dt. Ph2dt searches through phase files to find travel time information for event pairs at shared stations to create a network of event connectivity. It builds a chain of pairwise connections from one event to any other event, with the distance between connected events being as small as possible. Ph2dt requires multiple user inputs to build this network of events. This includes a maximum number of neighboring events within a user-defined radius; for this 
study the values were chosen to be 15 events within a $15 \mathrm{~km}$ radius. To reach the maximum number of neighboring events, only "strong" neighbors with more than a user-defined minimum number of links are considered. A link is confirmed when two events both have a travel time observation at a common station. A minimum number of five links was required for this study in order to define a "strong" neighbor. In addition, "weak" neighbors are still selected but do not count towards the maximum number of neighbors. The number of links saved for each event pair can be controlled by defining the minimum and maximum number of links to be selected for each pair; for this study the minimum and maximum number of links was set at 4 and 50 respectively. This means that pairs which have $<4$ links, or observations at 4 common stations, will be discarded. Analysts at AVO assign weight values between 1 (best) and 0 (worst) to the pick times for each station. A minimum pick weight of 0.0 was allowed to ensure that all recorded data was used. A maximum distance of $200 \mathrm{~km}$ between event pair and station was used. These specific inputs were chosen to preserve as many phase pairs as possible while minimizing the average offset distance between strongly linked events. For smaller swarms, slight modifications of the chosen input strategy discussed above were applied to create a stronger network of events. Ph2dt outputs two files used by HypoDD: (1) absolute travel times from earthquake catalogs for pairs of earthquakes, and (2) an event catalog including hypocenters and earthquake origin times. While our goal with ph2dt was to conserve as much of the data as possible, the weighting and re-weighting strategy chosen for HypoDD is slightly more restrictive.

The Waveform Cross Correlation Package was used to obtain adjusted arrival pick times for selected events. Similar earthquake waveforms (Figure 5) are produced when multiple events have the same rupture mechanics and share a nearly identical source-receiver path. Cross-correlating the data identifies how similar earthquake waveforms are, and calculates the time offset needed to align pairs of similar earthquake events in a time series. The offset is then 
applied to adjust the pick time in order to calculate precise differential times. The waveforms were then cross correlated with a window length of one second - from 0.5 seconds before analyst's time pick to 0.5 seconds after, with a maximum time shift of one second.

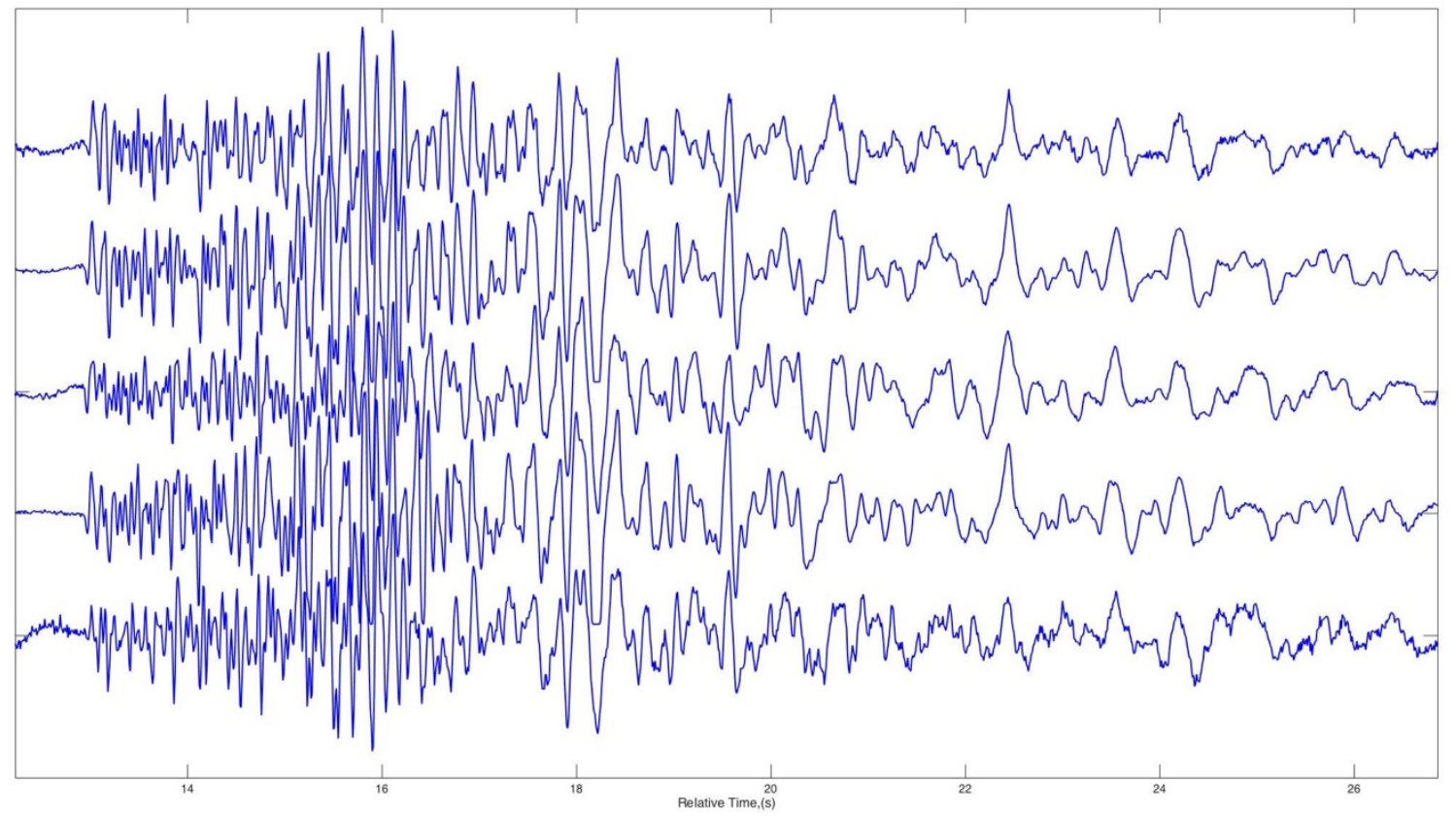

Figure 5: Plot showing five similar waveforms from 11/20/2005 at seismic station TASE. These events occurred in a tight cluster southeast of Takawangha. Similar earthquake waveforms are produced when multiple events have the same rupture mechanics and share a nearly identical source-receiver path.

Differential travel times from ph2dt and the Waveform Cross Correlation Package are used as input for HypoDD. HypoDD attributes the difference in travel times between two events observed at a common station to the spatial offset between those two events. This assumes that the distance between two events is small compared to the event-station distance and that the layered velocity model only varies with depth creating a nearly identical source-station ray path. The double-difference algorithm calculates the residual between observed and theoretical travel time differences for two events at a common station and correlates it with relative spatial adjustments of the hypocenters and origin times (Waldhauser and Ellsworth, 2000). Both the catalog and cross-correlated data sets were first tested individually to assess data quality and 
consistency before combining them. User designated inputs and weights (shown in Table 1) are applied in HypoDD to further strengthen the connectivity of events and create clusters.

The weighting scheme depicted in Table 1 is an example used mainly for larger swarms. We began by down weighting the cross-correlated data for the first 10 iterations; this allows the catalog data to restore the large-scale picture of Tanaga clusters. For iterations six and on, a maximum distance between catalog linked pairs of $10 \mathrm{~km}$ was applied to control outlier data. This means HypoDD ignores event pairs which have separation distances $>10 \mathrm{~km}$. In addition, for iterations six and on, a residual cutoff of $6 \sigma$ (standard deviation multiplied by a factor of six) was applied to catalog data to control outlier data. $6 \sigma$ was chosen based on testing different values to omit outlier data without discarding too many events. For iterations 11-25, we reweight catalog P-wave data from 1.0 to 0.4 , catalog S-wave data from 0.5 to 0.005 , and crosscorrelated P-wave data from 0.1 to 1.0 . This reweighting improves the locations of events with similar waveforms. A maximum separation distance (between linked pairs) of $10 \mathrm{~km}$ was assigned to cross-correlated data for iterations 11-20. This threshold was decreased to $6 \mathrm{~km}$ for the last 5 iterations, only allowing HypoDD to use cross-correlated data for linked pairs within 6 $\mathrm{km}$ of each other. Furthermore, a residual cutoff of $6 \sigma$ was applied to the cross-correlated data to control outliers in iterations 16-25. The number of iterations used for this technique was chosen based on specific HypoDD outputs; iterations can be stopped when the hypocenter adjustments and/or RMS residuals drop below the noise level of the data. It is important to note that a very similar but not always identical weighting and re-weighting strategy as discussed above and in Table 1 was used for each swarm. For instance, smaller swarms used the same strategy, but generally did not need as many iterations. In most cases, variations of this strategy included identical weighting and re-weighting for catalog and cross-correlated P and Swave data; however, residual thresholds and maximum distances between linked pairs were tailored depending on the number and spread of original locations. 
Table 1: Table showing the HypoDD weighting and re-weighting used for individual earthquake swarms. NITER defines the number of iterations to use the following weights. WTCCP and WCTCCS are the weights applied to cross-correlated P and S-wave data ( -9 assigns a weight of $0)$. WTCTP and WTCTS are the weights applied to catalog P and S wave data. WRCC and WRCT represent the residual threshold in seconds for cross-correlated and catalog data. WDCC and WDCT are the max distance $(\mathrm{km})$ between linked pairs for cross-correlated and catalog data.

$\begin{array}{ccccccccc}\text { NITER } & \text { WTCCP } & \text { WTCCS } & \text { WRCC } & \text { WDCC } & \text { WTCTP } & \text { WTCTS } & \text { WRCT } & \text { WDCT } \\ 5 & 0.1 & -9 & -9 & -9 & 1.0 & 0.5 & -9 & -9 \\ 5 & 0.1 & -9 & -9 & -9 & 1.0 & 0.5 & 6 & 10 \\ 5 & 1.0 & -9 & -9 & 10 & 0.4 & 0.005 & 6 & 10 \\ 5 & 1.0 & -9 & 6 & 10 & 0.4 & 0.005 & 6 & 10 \\ 5 & 1.0 & -9 & 6 & 6 & 0.4 & 0.005 & 6 & 10\end{array}$

HypoDD solves the double difference equations using either the conjugate gradient algorithm LSQR of Paige and Saunders (1982) or single value decomposition (SVD;

Waldhauser and Ellsworth, 2000). LSQR is able to solve large systems efficiently, however it known to have poor error assessment (Waldhauser and Ellsworth, 2000). SVD accurately provides information of least squares and hypocentral errors, however it can only process datasets of $<100$ events. In order to assess errors for our large dataset, we used the SVD method on subsets of the data. If relocations using SVD showed similar results to ones calculated using the whole data set with LSQR, then the SVD errors were averaged and extrapolated to represent the whole system.

\subsection{GISMO cross correlation and spectral analysis}

Waveforms were also cross correlated using the GISMO toolbox in MATLAB (Reyes and West, 2011) to identify clusters of similar events within large earthquake swarms. The Waveform Suite creates waveform objects, which contain all earthquake traces, to allow for easy data retrieval and processing. The Correlation Toolkit provides an easy to use interface to 
apply a variety of cross correlation techniques on waveform objects. We examined waveform objects primarily by using correlograms (a graphical representation of the similarity matrix) and dendrograms, which were implemented to identify discrete clusters of similar events. The dendrogram creates a hierarchical cluster tree, in which waveforms are grouped based on similarity. Subsets of event clusters can be made by trimming the cluster tree at certain threshold correlation coefficients. In this study, highly similar waveforms were classified when two waveforms had a correlation coefficient $>0.6$ (where 0 is completely uncorrelated and 1 is the autocorrelation). Not all waveforms had aligned P-waves, and in many cases two or more events which occurred within the same minute share identical waveform files. This made it difficult to cross-correlate only the event signals; therefore, we had to cross-correlate the entire waveform with GISMO. A minimum correlation coefficient of 0.6 was chosen based on examining the various waveforms at different values and determining that 0.6 was the lowest correlation value where waveforms were still visibly similar with the naked eye. Highly similar waveforms and their corresponding correlation coefficients can be seen in Figures 5 and 6. Highly correlated clusters were then stacked and examined spectrally.

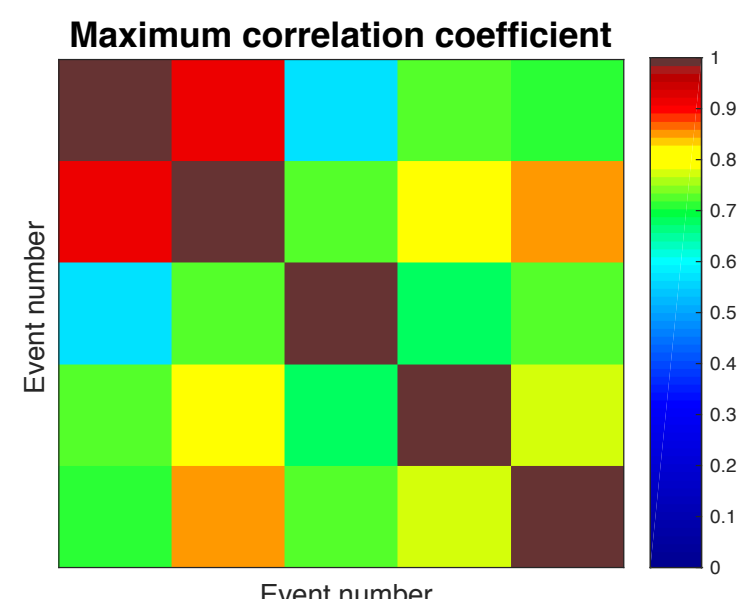

Figure 6: Correlogram showing the maximum correlation coefficients of five highly similar (correlation coefficient $>=0.6$ ) waveforms from $11 / 20 / 2005$. This plot was created in GISMO by cross-correlating the five different waveforms shown in Figure 5. The five brown blocks cutting diagonally across the plot represent each waveform being correlated with itself; therefore, the maximum correlation coefficients are equal to 1 because it is comparing identical waveforms. 
Different earthquake waveforms are associated with different source processes; for instance, brittle rupture on a fault will generate an abrupt high frequency wave known as a tectonic or volcano-tectonic (VT) earthquake depending on whether the associated stress is volcanic or resulting from tectonic processes. VT events may be isolated, clustered together in a swarm, and/or in a mainshock-aftershock sequence. In this study, we consider events to be VTs if they have impulsive P-wave arrivals and are dominated by frequencies above $5 \mathrm{~Hz}$. Volcanic tremors known as LP events are dominated by lower frequencies (typically $0.5-5 \mathrm{~Hz}$ ) and are attributed to fluid movement (magma, hydrothermal fluid, or gas). Some spectra exhibit overtones, suggesting that the system is resonating. LP events typically have shallow hypocenters $(<10 \mathrm{~km})$ and may migrate with the movement of fluids (Chouet, 2003). Deep, long period (DLP) events, which occur roughly between 10 and $50 \mathrm{~km}$ depths, are commonly interpreted to indicate magma transport in the lowermost crust and uppermost mantle (Power et al., 2004). Hybrid events blend aspects of both VT and LP events. Hybrid events have an abrupt high frequency ( $>5 \mathrm{~Hz}$ ) onset followed by low frequencies $(<5 \mathrm{~Hz})$ and are thought to be associated with brittle rupture accompanied by fluid movement (Lahr et al., 1994). Examples of VT, LP, and hybrid waveforms and power spectrums are shown in Figure 7.

We calculated power spectra for stacked earthquakes in each cluster. In some cases where the waveform had excessive noise at low frequencies a high-pass filter was applied to filter out extremely low frequencies $(>0.5 \mathrm{~Hz})$ such as microseisms. High-pass filters were only applied to high frequency signals when one or two stations showed long period rolls through the entire waveform. 

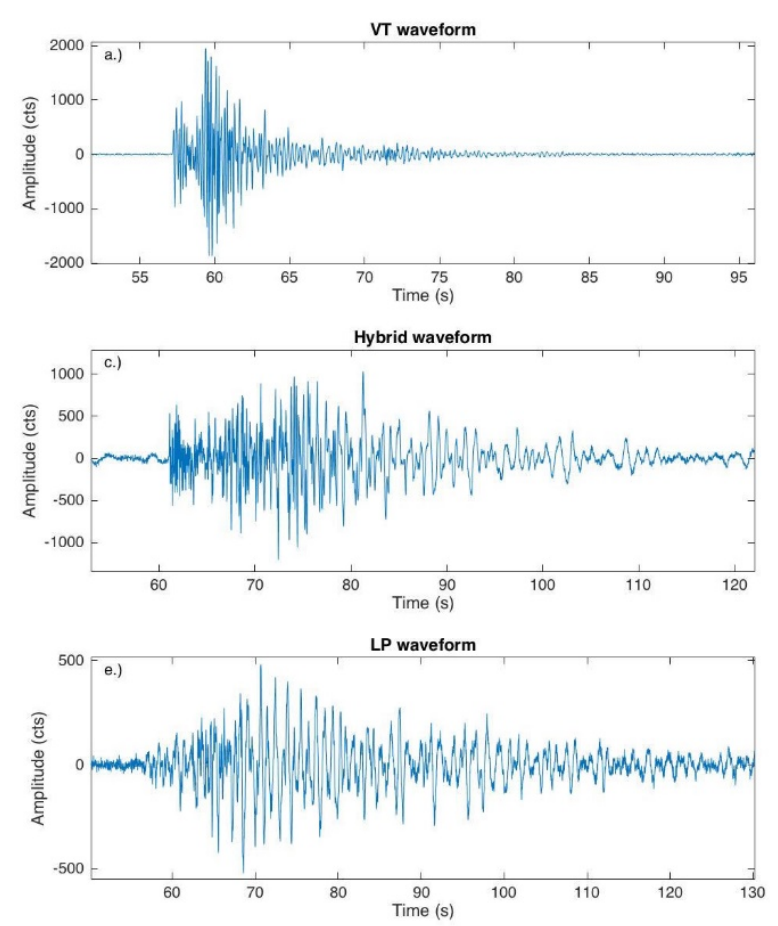
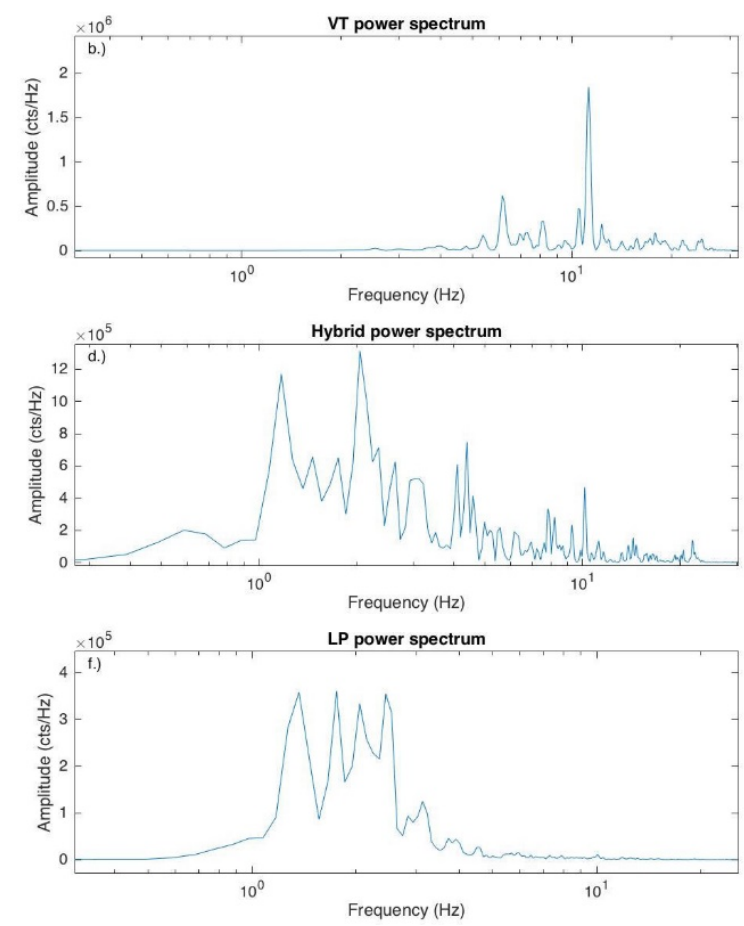

Figure 7: Plots a and b show the waveform and power spectrum of a VT event which occurred in June 2009 at seismic station TAFP. VT waveforms have abrupt P-wave arrivals, clear Swave arrivals, and are dominated by frequencies $>5 \mathrm{~Hz}$. Plots $\mathrm{c}$ and $\mathrm{d}$ show the waveform and power spectrum of a hybrid event which occurred in October 2005 at seismic station TAFL. Hybrid waveforms have abrupt $\mathrm{P}$-wave arrivals with often less distinct S-wave arrivals and have high frequency onsets followed by low frequencies. Hybrid power spectrums show a mix of both low and high frequencies, but often show higher amplitudes of frequencies $<5 \mathrm{~Hz}$. Plots e and $\mathrm{f}$ show the waveform and power spectrum of a LP event which occurred in May 2008 at seismic station TANO. LP waveforms have emergent $P$-wave onsets and indistinct $S$-wave arrivals. LP power spectrums are dominated by frequencies $<5 \mathrm{~Hz}$.

\section{Results:}

In our dataset, Tanaga earthquakes occur both as isolated (temporally and/or spatially) events and together in episodes of heightened seismicity. Episodes of heightened seismicity can be identified as either earthquake swarms, a cluster of small magnitude events that occur both spatially and temporally close to each other, or mainshock-aftershock sequences, in which a large magnitude event is followed by hundreds of smaller magnitude events as the fault settles back into equilibrium (Figure 8). Earthquake swarms and mainshock-aftershock sequences make up nearly $60 \%$ of events in this dataset. 


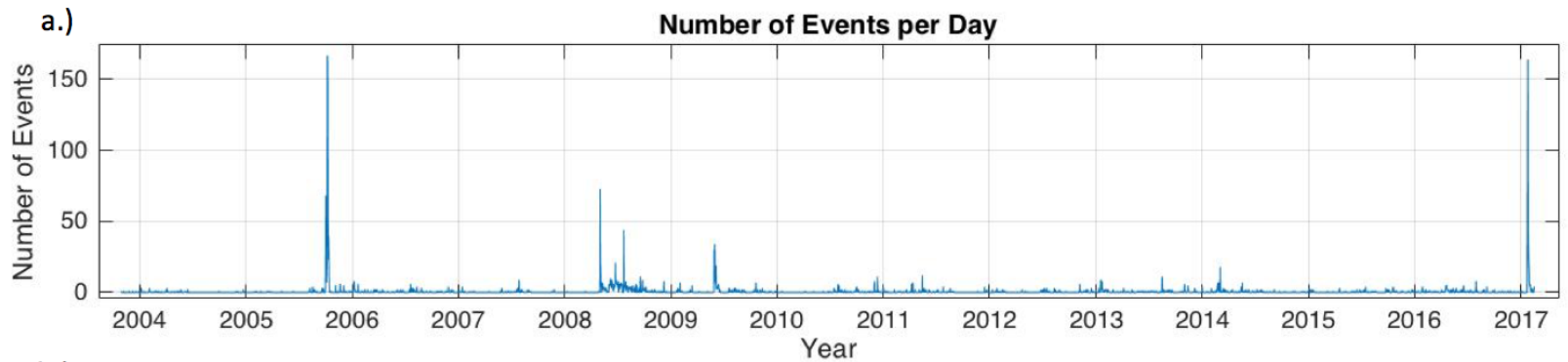

b.)

Event Magnitudes

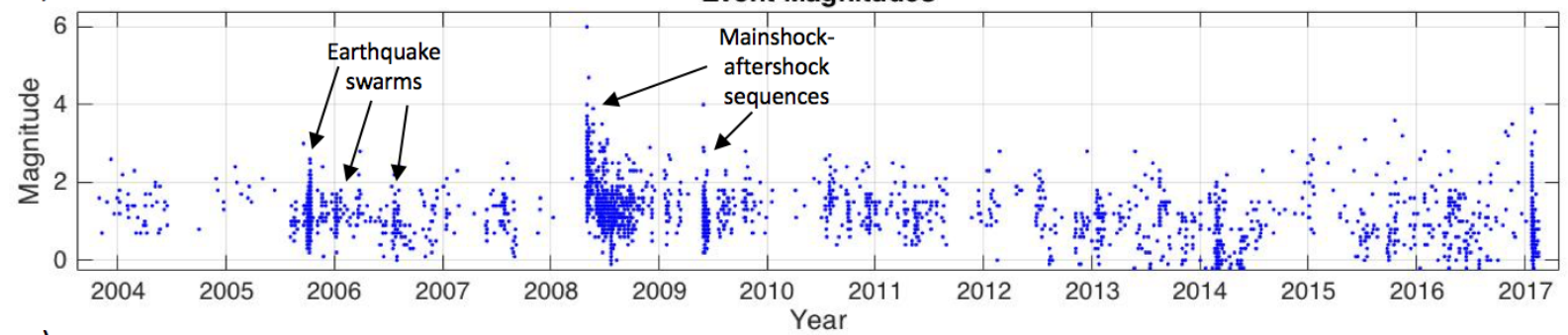

c.) $\times 10^{17} \quad$ Cumulative Energy Released

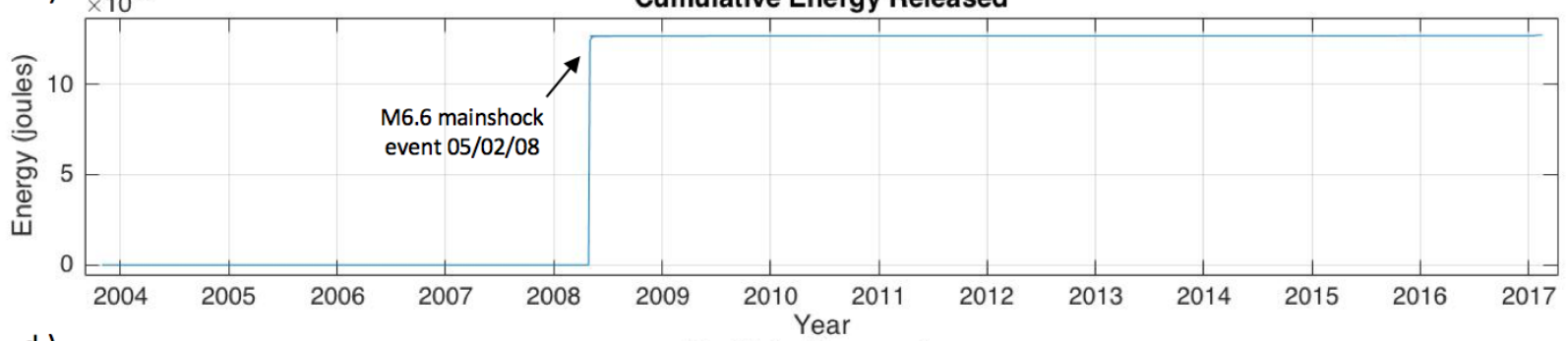

d.)

Depth to Hypocenter

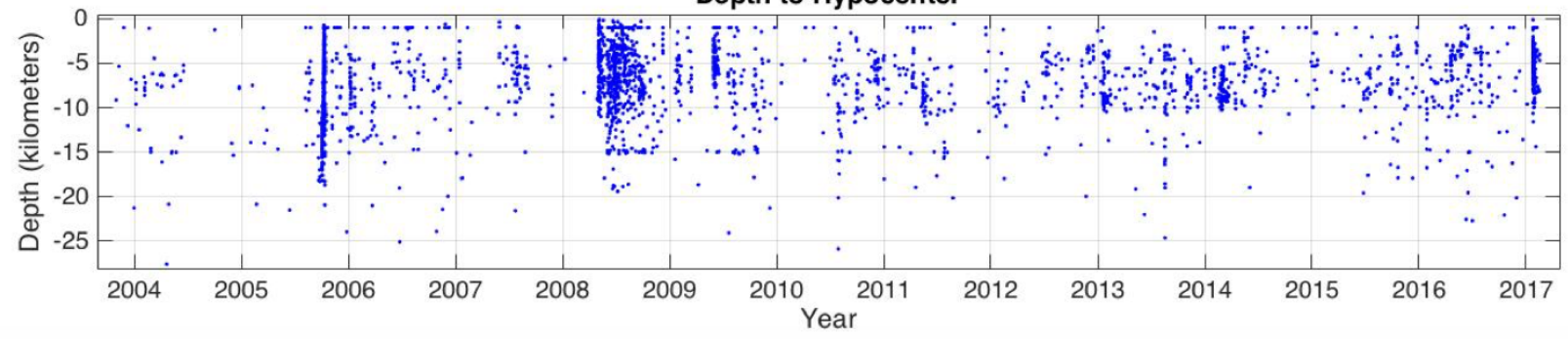

Figure 8: a.) The number of daily earthquakes located at Tanaga Island, Alaska. b.) earthquake magnitudes. c.) cumulative energy released over time for the whole seismic record. d.) depth to each hypocenter for each individual earthquake in the seismic record. The single large jump in cumulative energy release is caused by the M6.6 mainshock event in May 2008. The 2008 and 2009 swarms represent mainshock-aftershock sequence. In contrast, a large swarm (>150 events) in late 2005 of magnitude $<5$ earthquakes is virtually invisible on the cumulative energy graph. 
The catalog locations, based on picks made by AVO analysts, have average horizontal and vertical location errors of $1027 \mathrm{~m}$ and $1528 \mathrm{~m}$ respectively. After relocation using HypoDD, the original location errors were reduced by a factor of three; the average horizontal and vertical errors of HypoDD relocated events are $249 \mathrm{~m}$ and $525 \mathrm{~m}$ respectively (Table 2). HypoDD relocations, calculated using the complete catalog dataset, are shown in Figure 9 and 10. Although the hypocenters are not significantly different from the catalog values, the relocation process gives us confidence in their locations. In order to better constrain specific clusters of earthquakes and reduce errors, we focus our study on relocating individual earthquake swarms and mainshock-aftershock sequences. Furthermore, locating individual clusters facilitated the use of cross-correlated arrivals; little to no similarity was observed between events in different clusters. Figure 9 shows seismic activity occurring in clusters both below the volcanic centers and in offshore locations. Other regions are characterized by diffuse seismicity. These locations include but are not limited to: a) $40 \mathrm{~km}$ southwest of Tanaga at depths between 4-13 $\mathrm{km}$; b) the WTVC at depths between 4-15 km; c) $15 \mathrm{~km}$ south of Tanaga Island at depths between 7-12 km (Figure 9). The following results are grouped by location - beginning with seismicity clustered below the island and followed by coastal and offshore seismicity. 

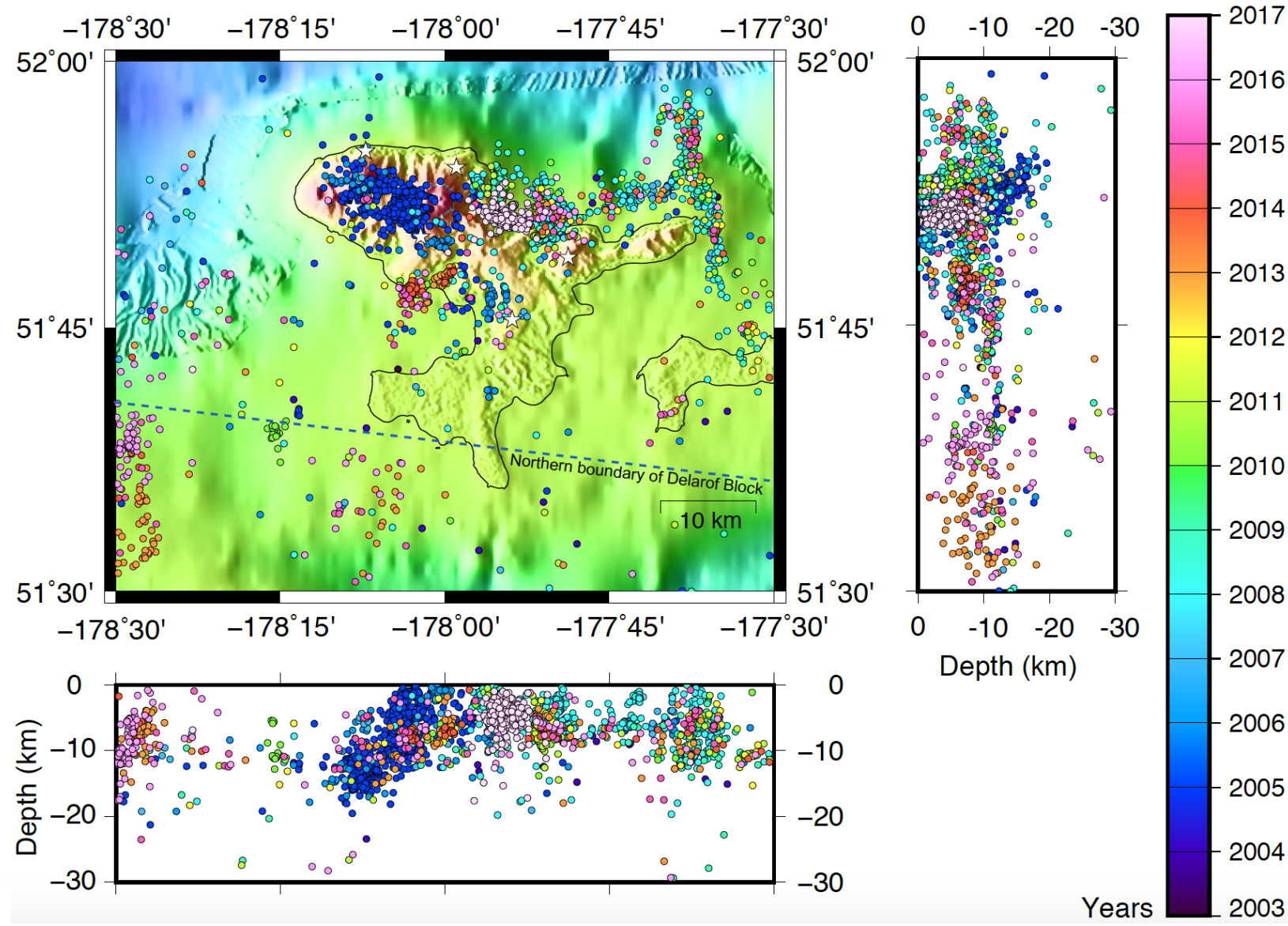

Figure 9: Map of Tanaga Island, Alaska displaying HypoDD relocations (colored circles) of seismicity between October 2003 - February 2017. White stars show seismic station locations. Depths (in $\mathrm{km}$ ) of hypocenters within the map area are projected below and to the right of the map on a E-W plane (looking north), and on a N-S plane (looking west). These relocations were calculated using the entire catalog dataset and the available cross-correlated data. 


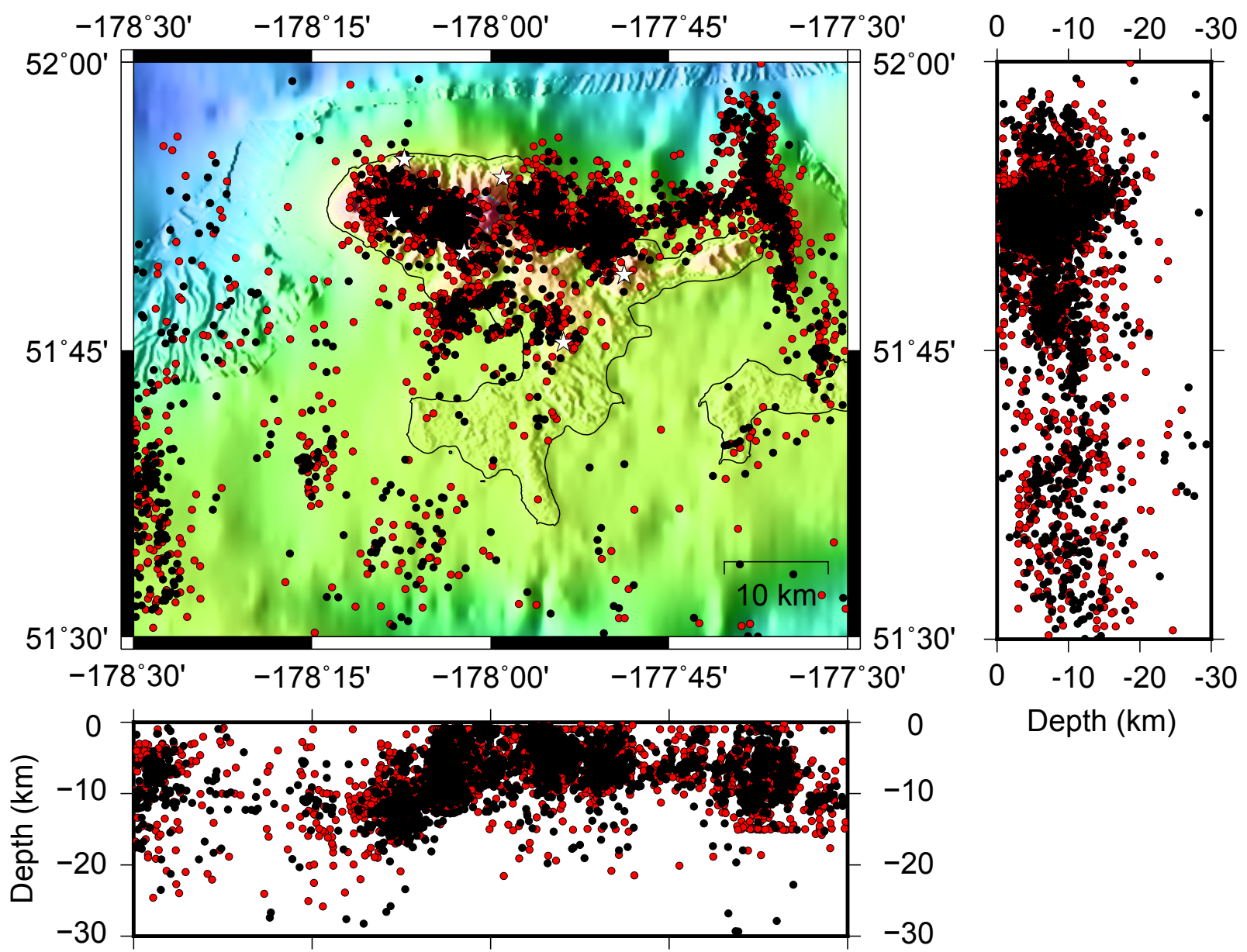

Figure 10: Map of Tanaga Island, Alaska displaying original catalog locations (red circles) and HypoDD relocations (black circles) of seismicity between October 2003 - February 2017. White stars show seismic station locations. Depths (in $\mathrm{km}$ ) of hypocenters within the map area are projected below and to the right of the map on a E-W plane (looking north), and on a N-S plane (looking west). These relocations were calculated using the entire catalog dataset and the available cross-correlated data. 
Table 2: Table showing the averages of RMS errors in seconds and location errors in meters for events within each swarm. Error values are displayed for both original hypocenter locations (picked by AVO analysts) and relocated events after HypoDD. Some swarms were missing original error calculations. RMS error values are shown for both the catalog data and crosscorrelated data if applicable.

\begin{tabular}{ccccccc}
\multicolumn{2}{c}{ Original Locations } & \multicolumn{5}{c}{ HypoDD Relocations } \\
$\begin{array}{c}\text { Horizontal } \\
\text { error }\end{array}$ & $\begin{array}{c}\text { ertical } \\
\text { error } \\
(\mathbf{m})\end{array}$ & $\begin{array}{c}\text { RMS } \\
\text { error }\end{array}$ & $\begin{array}{c}\text { Horizontal } \\
\text { error }\end{array}$ & $\begin{array}{c}\text { Vertical } \\
\text { error }\end{array}$ & $\begin{array}{c}\text { RMS error } \\
\text { catalog }\end{array}$ & $\begin{array}{c}\text { RMS error } \\
\text { cross- } \\
\text { correlated (s) }\end{array}$ \\
\hline NA & NA & 0.1059 & 174 & 244 & 0.0553 & 0.0844 \\
1056 & 1759 & 0.1437 & 194 & 1295 & 0.0872 & 0.0736 \\
1029 & 1626 & 0.1536 & 196 & 232 & 0.0962 & 0.1122 \\
NA & NA & 0.1141 & 154 & 258 & 0.1273 & 0.1020 \\
1256 & 2350 & 0.2087 & 289 & 412 & 0.1328 & 0.1897 \\
1039 & 1714 & 0.1017 & 129 & 259 & 0.0596 & NA \\
NA & NA & 0.1422 & 455 & 540 & 0.2503 & 0.3473 \\
NA & NA & 0.0911 & 300 & 1296 & 0.1592 & 0.1119 \\
NA & NA & 0.0988 & 429 & 819 & 0.0441 & 0.0010 \\
943 & 1143 & 0.1204 & 275 & 480 & 0.0947 & NA \\
1055 & 1107 & 0.1316 & 208 & 237 & 0.0888 & NA \\
808 & 998 & 0.1112 & 184 & 226 & 0.0801 & 0.0949 \\
1027 & 1528 & 0.1270 & 249 & 525 & 0.1063 & 0.1256 \\
& & & & & & \\
\hline
\end{tabular}

\subsection{Activity below Tanaga Island}

\subsubsection{Takawangha seismicity}

The first large earthquake swarm recorded by the Tanaga seismographic network began on October 1, 2005. This swarm consisted of nearly 600 events and took place at depths of 1- 
$17 \mathrm{~km}$ in a region spanning the TVC (Figure 11). Although the majority of events occurred on

October 1-9, seismic unrest lasted through November.
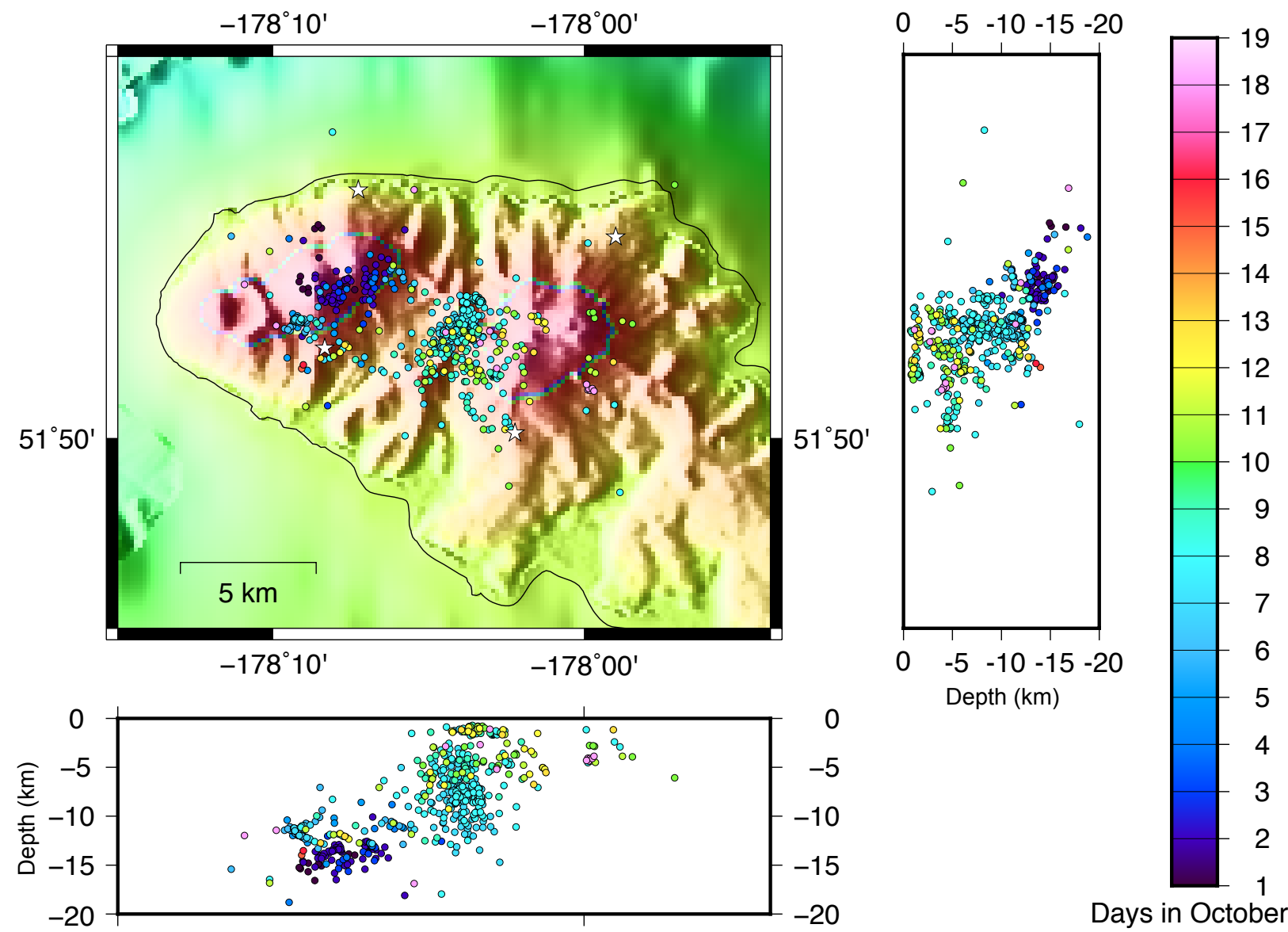

Days in October

Figure 11: Map of Tanaga Island, Alaska showing the October, 2005 seismic swarm. White stars are seismic stations. Colored dots are hypocenters, colored by the date in October. Pink colored dots are hypocenters from November 2005. Depths (in $\mathrm{km}$ ) of hypocenters within the map area are projected below and to the right of the map on a E-W plane (looking north), and on a N-S plane (looking west).

Between October 1-6, nearly 160 events occurred 11-18 km below the summit of Tanaga Volcano in a confined cluster (Figure 11). Cross-correlation analysis (Figure 12) reveals three distinct clusters of similar events during this time: one prior to 04:00 UTC on October 2, one after 04:00 on October 2-3, and one cluster on October 5-6. Although the waveforms of these three distinct cluster varied, they were all clearly VT earthquakes with 
abrupt $\mathrm{P}$ and S-wave arrivals and high-frequency waveforms. The power spectrums of these events were dominated by frequencies between 4-8 Hz with some weaker energy between 3-4 and 8-13 Hz.

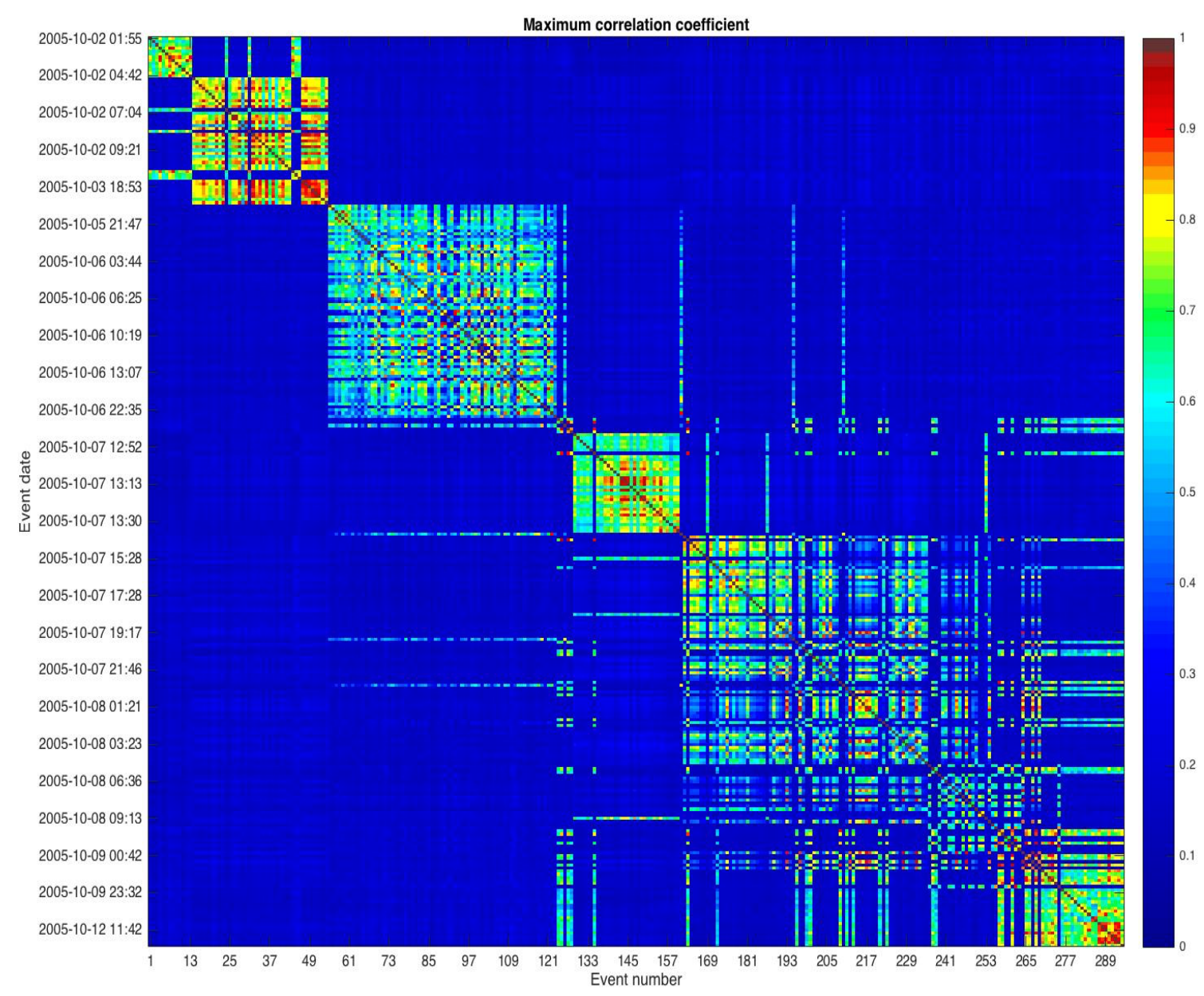

Figure 12: Correlogram for earthquakes in the October, 2005 swarm. Correlograms show how similar event waveforms are to one another (0/blue meaning not similar at all and $1 /$ dark red meaning nearly identical waveforms). Both axes are the same in this case, with event 1 on the $x$-axis being the same as 2005-10-02 01:55 on the y-axis. The diagonal strip of correlation coefficients equal to 1 (cutting from top left to bottom right across the grid) is the autocorrelation. Similarity of these events can be separated into clusters: October 2-3, 2-4, 5-6, early on the 7, 7-9, and 9-17. 
Activity began to shallow and shift east-southeast toward Takawangha on October 7. Between October 7-9, about 300 events occurred in a vertical structure 1-15 km below Takawangha and the amphitheater ridge. Cross-correlation analysis shows that the events during this time can be separated into two distinct clusters: one cluster taking place before 14:00 on October 7 , and one cluster after 14:00 on October 7 through 9 . The earlier cluster of events, before 14:00 on October 7, were high frequency events with abrupt P and S-wave arrivals. Power spectra of these events were dominated by frequencies between 3.3-6 Hz with slightly weaker frequencies between $6-14 \mathrm{~Hz}$. The later cluster of events showed dominant frequencies between $3-10 \mathrm{~Hz}$ with the strongest signals near 4,6 , and $8 \mathrm{~Hz}$.

Beginning on October 8 , many shallow $(<4 \mathrm{~km})$ hypocenters surrounding Takawangha were observed. Events with the shallowest $(<1 \mathrm{~km})$ hypocenters occurred just west of Takawangha and below the amphitheater ridge. During this time, a linear trail of events occurred $\sim 5 \mathrm{~km}$ southwest of Takawangha, shallowing to the south near seismic station TASE. Additionally, events at depths $<3 \mathrm{~km}$ locate southeast of Takawangha. Many of these shallow events were hybrid events with abrupt $\mathrm{P}$-waves and dominated by frequencies $<5 \mathrm{~Hz}$. These areas surrounding Takawangha remained active throughout the rest of the swarm.

Seismic activity began to decrease after October 9 with about 80 events occurring between Oct 9-17. Relocations for these events varied from $<1 \mathrm{~km}$ below Takawangha to about $17 \mathrm{~km}$ below Tanaga. About 45 of these high frequency events were highly similar waveforms with abrupt P-wave arrivals and dominant frequencies between 4-9 Hz accompanied by less dominant frequencies between $2.7-4$ and $9-15 \mathrm{~Hz}$. The deep events near Tanaga often occurred preceding or synchronous with shallow events near Takawangha and/or the amphitheater ridge. Some of the shallow events surrounding Takawangha during this time were hybrid events with abrupt high frequency onsets followed by high relative amplitudes of low 
frequencies. This included two small clusters just east and southeast of Takawangha on October 10 and 11 . There was no recorded seismicity on October 14 , and only two deep events below Tanaga on October 15 and 16 in the dataset.

At 10:53 (UTC) on October 17, a roughly 8 minute-long episode of volcanic-tremor was recorded by Tanaga stations, with dominant frequencies that were between 0.8 and $5 \mathrm{~Hz}$, but recordable up to $10 \mathrm{~Hz}$. The location for this event is uncertain, however the signal arrived first and had the strongest amplitudes at TASE, followed by TAFP (Figure 1). TASE and TAFP recordings were both clipped, meaning the amplitudes of the signal exceeded the (dynamic range of the instrument and associated telemetry) threshold of the instrument's ability to measure. The first 6 minutes of the tremor had a nearly consistent signal with a long emergent onset and some periods of increased amplitude (Figure 13); however, the final 1.7 minutes of the tremor had dramatically reduced amplitude and showed similar frequencies as the rest of the signal. At all stations the tremor signal exhibited spectra dominated by a series of sharp harmonic peaks between 0.8 and $5.6 \mathrm{~Hz}$ (Figure 14). Particle motions are often calculated to determine the first displacement/motion of the P-wave. Figure 15 shows the particle motion dominated by motion in the north-south direction, calculated for the onset of the tremor at the only 3-componant station, TAFP. 


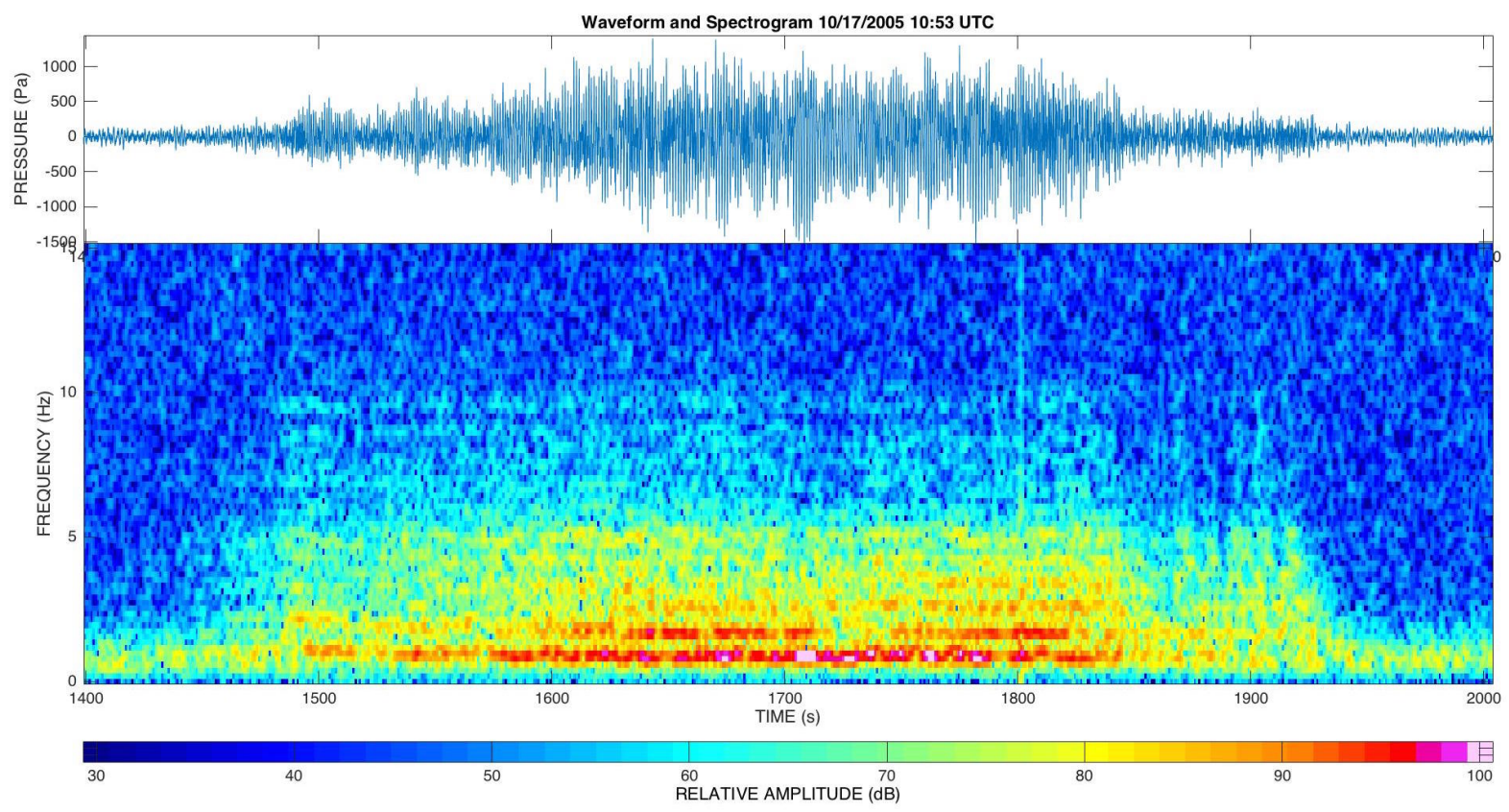

Figure 13: Waveform (above) and spectrogram (below) of the October 17, 2005 tremor event recorded at TAFL. The spectrogram shows the change in frequency and amplitude through time. Long stripes of consistent harmonic frequencies can be seen in the colored bands of red and/or pink.

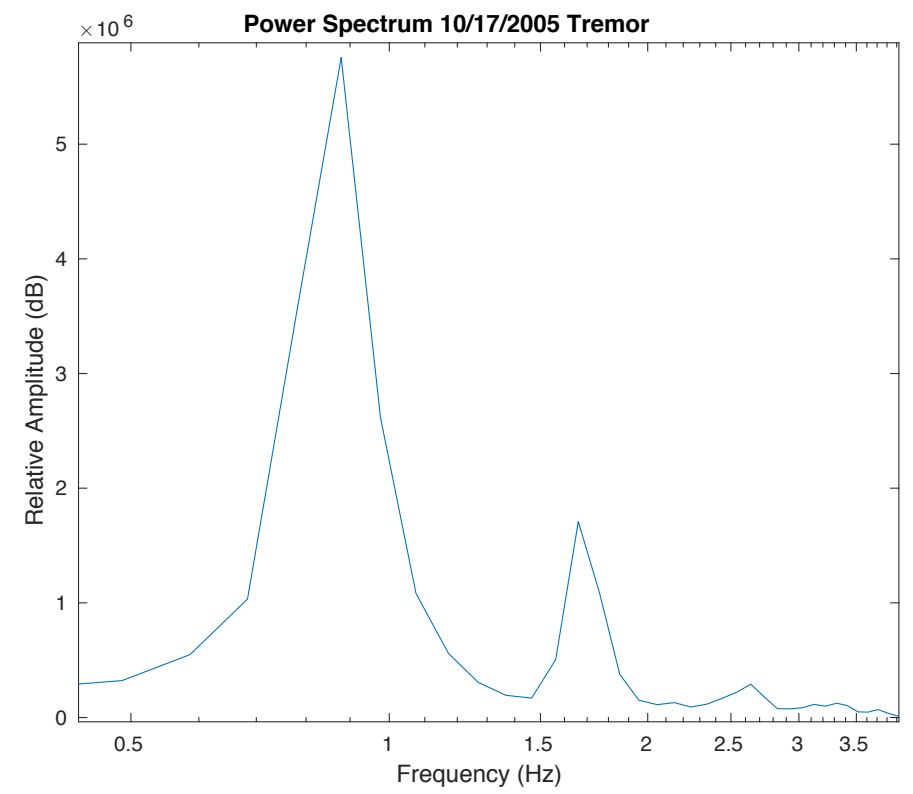

Figure 14: Power spectrum of the October 17, 2005 tremor event recorded at TAFL. This plot shows multiple sharp peaks at harmonic frequencies. The frequencies with greatest amplitude in the signal are at $0.88,1.66$, and $2.64 \mathrm{~Hz}$. 


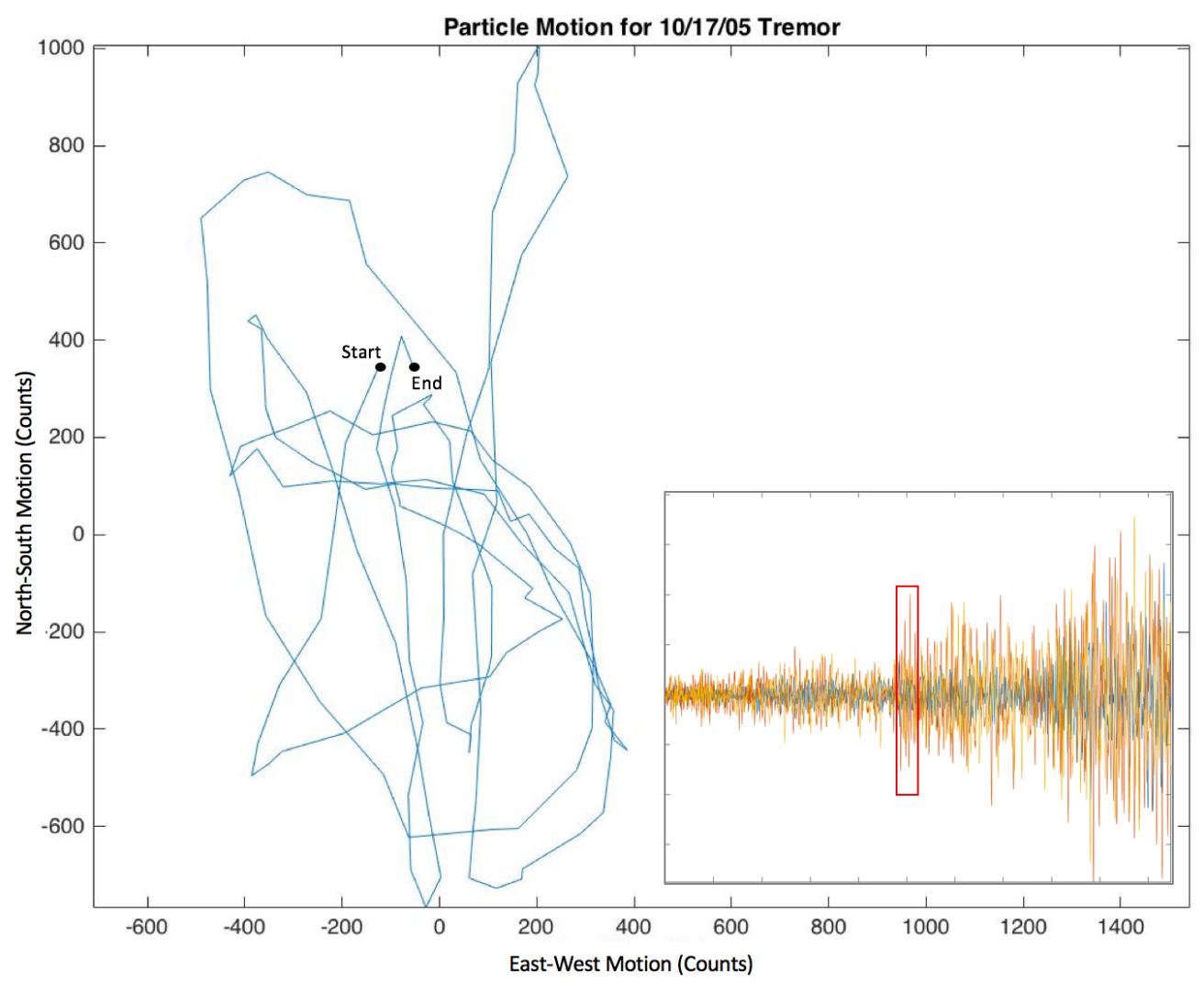

Figure 15: Horizontal surface motion at station TAFP, in response to the tremor recorded at 10:53 UTC on October 17, 2005. Because the emergent nature of the tremor onset, it is difficult to determine the first initial motion; nonetheless, particle motion is mainly dominated by motion in the north-south direction. The particle motion was calculated from a 2 second portion of the onset of the tremor event (red box).

On October 24, two hybrid events occurred for which we have no catalog locations.

These two events have a high frequency onset $(5-14 \mathrm{~Hz})$ followed by a 10 second signal dominated by low frequencies $(2-4 \mathrm{~Hz})$. The recordings are clipped on four of the Tanaga stations. First motions calculated at TAFP showed north-south dominated particle motions, similar to the October 17 tremor event.

Seismicity remained quiet until November 5 when three deep events $(\sim 15 \mathrm{~km})$ below Tanaga preceded four shallow events below the amphitheater ridge. In addition, a shallow (4 $\mathrm{km}$ ) cluster of six events took place $3 \mathrm{~km}$ southeast of Takawangha on November 20-21. The waveforms of these shallow events were highly similar (Figures 5 and 6) and were hybrid events dominated by frequencies $<4 \mathrm{~Hz}$. 
After the events in November 2005, the Takawangha region remained relatively quiet until a small swarm began on July 15, 2006. This swarm consisted of 27 tightly clustered high frequency events $4 \mathrm{~km}$ due south of Takawangha (western cluster in dark blue; Figure 16). All events were shallow $(<2 \mathrm{~km})$, had small magnitudes $(<\mathrm{M} 2.2)$ with easily identifiable P and Swave arrivals. Only six events in this cluster were highly similar, with dominant frequencies between $5-10 \mathrm{~Hz}$ with the highest amplitude at $8 \mathrm{~Hz}$. Many event waveforms from the shallow cluster displayed abrupt high frequency onsets followed by low frequencies, which we identified as hybrid events.

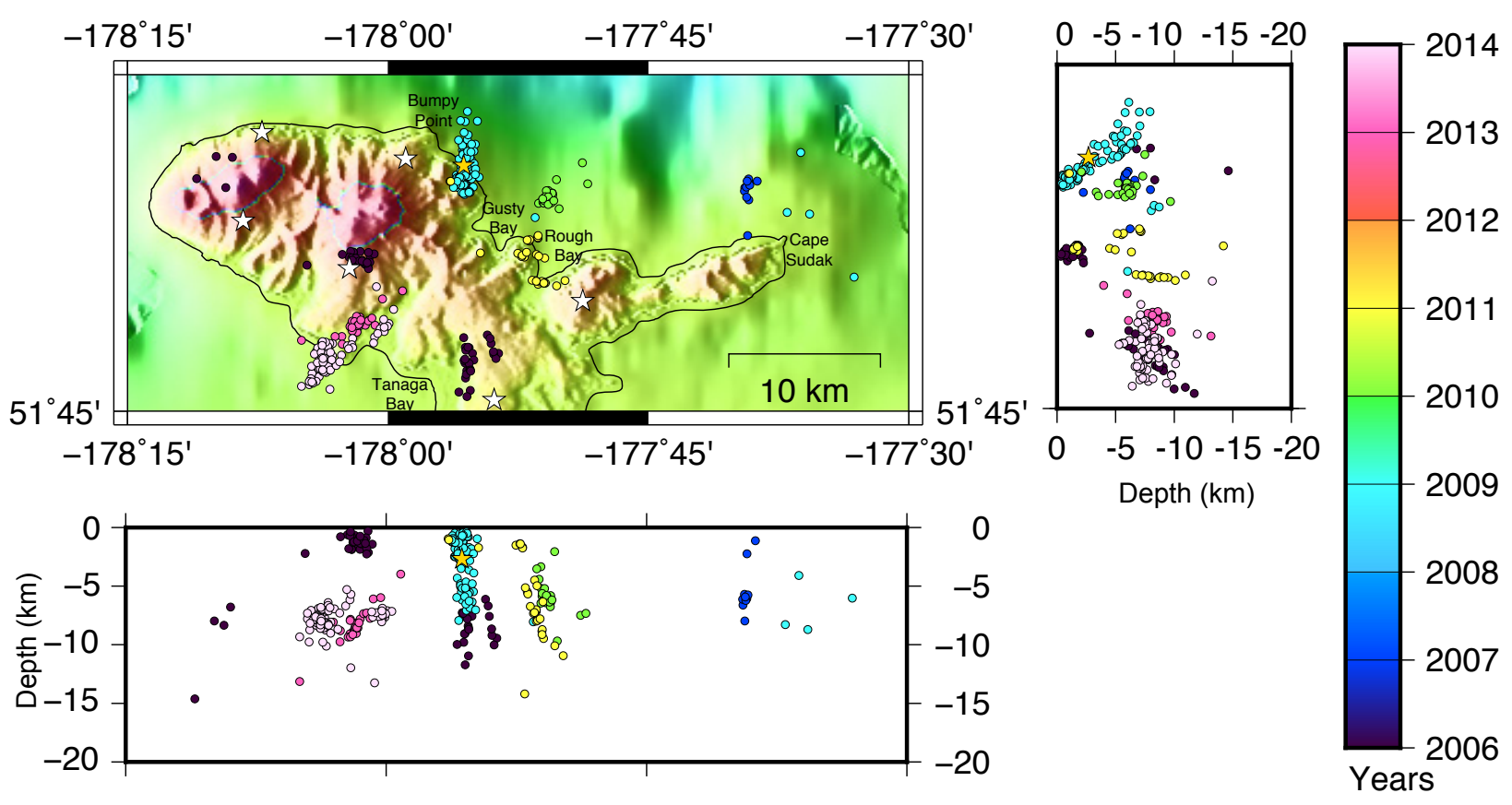

Figure 16: Map of Tanaga Island, Alaska showing smaller seismic swarms which occurred between 2006-2014. White stars are seismic stations. Circles are hypocenters, color coded by date. The yellow star is the 2009 M4.0 mainshock event. Depths (in km) of hypocenters within the map area are projected below and to the right of the map on a E-W plane (looking north), and on a N-S plane (looking west). The 2009, 2013, and 2014 swarms were relocated only using catalog locations. All other swarms were relocated using both catalog and crosscorrelated data. 


\subsubsection{Seismicity below WTVC (Tanaga, East Tanaga, and Sajaka)}

Excluding the 2005 swarm, only 52 events of the 3,000+ event data set occurred beneath the WTVC. These events did not occur as swarms and rarely occurred on the same day as another; often taking place days, months, or years apart. The events below the Tanaga volcanic cluster are limited to 2 events from 2003-2004, 43 events from 2006-2007, 1 event in 2011, and 6 events in 2015 (Figure 17). Four of the events below Tanaga in 2006 coincide with the July 2006 swarm. Although most of these events cluster between 4-8 km beneath Tanaga Volcano, activity is also observed at depths between $5-20 \mathrm{~km}$ beneath the north flank of Sajaka Volcano and between Tanaga and East Tanaga. Most of the events below the Tanaga volcanic cluster were high frequency events with dominant spectra between $5-25 \mathrm{~Hz}$. Five hybrid events occurred $5 \mathrm{~km}$ south of Tanaga in October of 2015 and exhibited lower frequencies than the rest of the Tanaga events, with frequencies of $<5 \mathrm{~Hz}$. These five events are 4-6 km below the surface and trend northeast/southwest. The first two events of this cluster were M1.7 and M3.6, followed by three more <M0.8 events. 


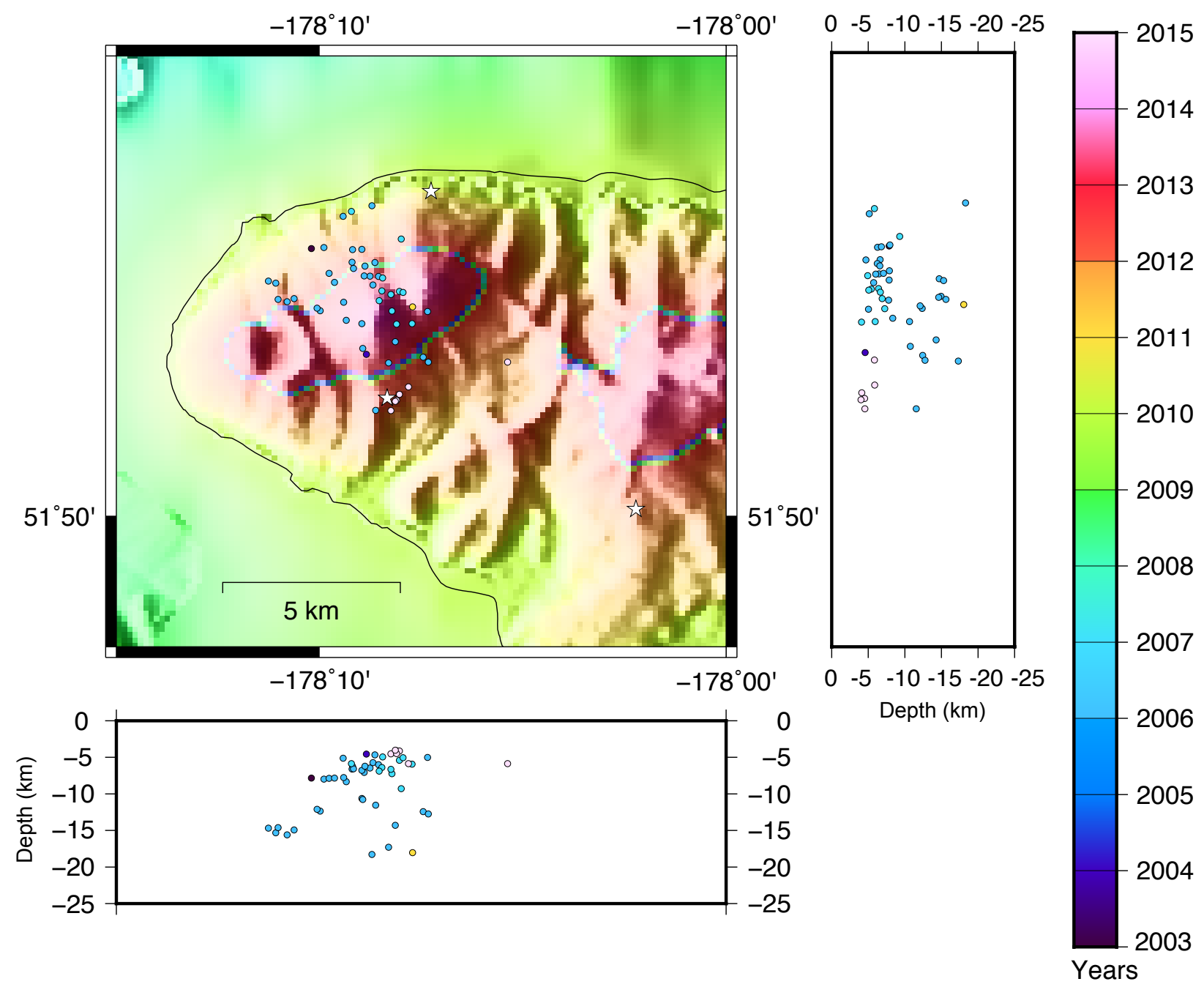

Figure 17: Map of the northwest portion of Tanaga Island, Alaska showing all relocated seismicity between 2003-2017 (excluding the 2005 swarm data) beneath the WTVC. White stars are seismic stations. Colored dots are hypocenters, colored by the date. Depths (in $\mathrm{km}$ ) of hypocenters within the map area are projected below and to the right of the map on a E-W plane (looking north), and on a N-S plane (looking west). 


\subsubsection{Central Tanaga Island seismicity}

Episodic activity throughout the data set was observed in the central lowland of Tanaga Island, about $25 \mathrm{~km}$ southeast of Takawangha. This includes a swarm of 33 high frequency events in January 2006 (Figure 16). The 2006 cluster of earthquakes can be separated into two episodes; the first took place from January 5-9, and the second on January 21 . This swarm consisted entirely of small magnitude events $(<M 2)$. Relocated hypocenters revealed more structural detail. Two linear features are found between $5-10 \mathrm{~km}$ below the surface, trending with azimuths of 346 and 340 degrees, and plunging to the south. The later episode occurred about $1 \mathrm{~km}$ east and just beneath the first episode. Only eight of these events were highly similar, however all showed clear P and S-wave arrivals. The dominant frequencies were between $3-10 \mathrm{~Hz}$ with the strongest signal at $6 \mathrm{~Hz}$. Other non-swarm-like clusters of activity were observed in this region between 2007-2016 (Figure 9).

\subsection{Offshore and coastal seismicity}

\subsubsection{North/east of Cape Sudak}

On July 28-29, 2007, a swarm of 13 events occurred just north of Cape Sudak (Figure 16); prior to this time, only a few isolated events had been recorded in this region. These events had small magnitudes (range from M0.8 to 1.7) and were clustered about $25 \mathrm{~km}$ east of Takawangha. Most of the swarm took place at depths of $6 \mathrm{~km}$ in a tight cluster. Nearly all of the waveforms of this swarm were highly similar and showed clear P and S-wave arrivals. Dominant waveform frequencies were between $3-8 \mathrm{~Hz}$ with the strongest signal at 4-5 Hz.

The region offshore Cape Sudak remained relatively quiet after the small swarm in 2007 until a large mainshock-aftershock sequence in 2008. On May 2, 2008, a M6.6 earthquake was recorded just east of Cape Sudak. Following the mainshock, 143 aftershocks located by AVO 
took place in this region through July. The main offshore cluster (cluster 1), which included the M6.6 event, is located just east of Cape Sudak along a line that trends 346 degrees (Figure 18). Two other clusters of $200+$ events took place shortly after the mainshock: a) about $15 \mathrm{~km}$ due east of Takawangha in Rough Bay (cluster 2); b) about 8 km northeast of Takawangha near Bumpy Point (cluster 3). Nearly 100 of the events which took place after the mainshock were $>\mathrm{M} 2.5$.

The May 2 mainshock was a shallow strike-slip event, only 8.7 km deep (Figure 18). The moment tensor suggests two possible fault planes: one striking 350 degrees and dipping 86 degrees to the east, and another striking 259 degrees and dipping 74 degrees to the north (Ekström et al., 2012). Cluster 1 is very linear, trending roughly 346 degrees and stretching for nearly $25 \mathrm{~km}$ (Figure 18). Hypocenters of this cluster occurred between 1-12 km depth, in a near vertical lineation. Waveforms from this sequence were not highly similar, however the majority of events were dominated by frequencies $6-18 \mathrm{~Hz}$. By the end of July this region returned to normal levels of background seismicity. 

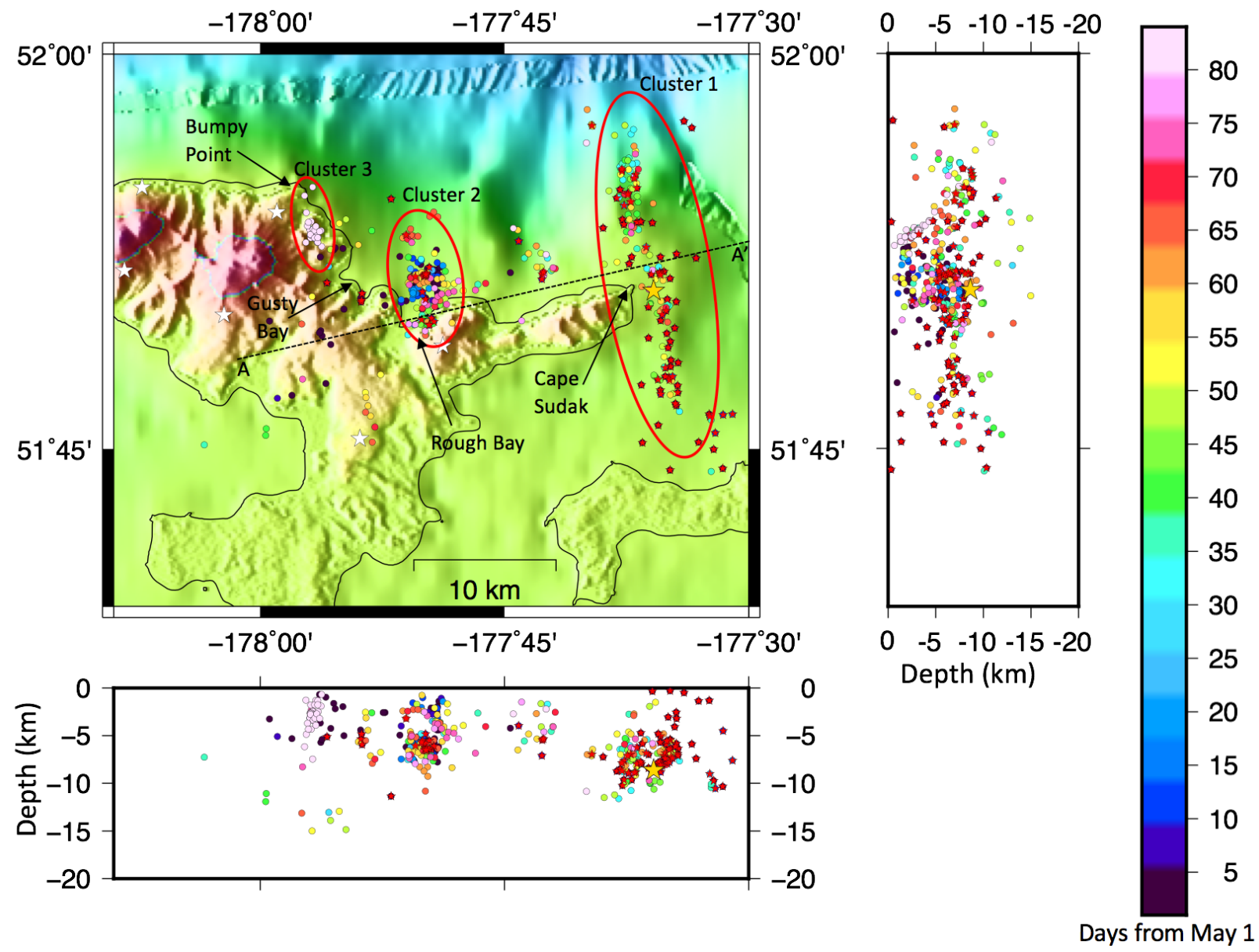

Figure 18: Map of Tanaga Island, Alaska seismicity showing the May-July, 2008 mainshockaftershock sequence. White stars are seismic stations. Colored dots are earthquake hypocenters, colored by the number of days from May 1. Red stars are M>2.5 events. The yellow star is the May 2 M6.6 mainshock event. Depths (in km) of hypocenters within the map area are projected below and to the right of the map on a E-W plane (looking north), and on a $\mathrm{N}-\mathrm{S}$ plane (looking west).

\subsubsection{Rough Bay}

Rough Bay exhibited consistent isolated seismicity throughout the dataset with a few swarm episodes. In 2008, seismic unrest in Rough Bay began immediately following the M6.6 mainshock event. This activity has depths between 1-12 km and is labeled on Figure 18 as cluster 2 . It is broadly linear with an approximate trend of 348 degrees and about $8 \mathrm{~km}$ in extent in the north-south direction. Many of the events comprising of cluster 2 had similar waveforms, showing clear $\mathrm{P}$ and S-wave arrivals and dominant power spectra between $5-7 \mathrm{~Hz}$ and another 
strong signal near $11 \mathrm{~Hz}$. During this swarm we observed four LP events about $5.5 \mathrm{~km}$ below Rough Bay. These events had indistinct $P$ and S-wave arrivals and showed dominant spectra between 1-3 Hz. Activity began to taper toward the end of July.

Another swarm of 30 events occurred below Rough Bay in December, 2010 (Figure 16). Depths ranged from 1-9 km and delineated a near vertical structure. Both $\mathrm{P}$ and $\mathrm{S}$-wave arrivals of highly similar events were distinct. The dominant frequency range was between 3-11 $\mathrm{Hz}$ with the highest amplitudes near 4 and $10 \mathrm{~Hz}$.

Only four months after the December 2010 cluster, a similar location offshore Rough Bay became active again. From April 8 to May 15, 29 events occurred in three separate episodes (Figure 16). The first occurred on April 8 and consisted of seven events with depths of 6-10.5 km. The second cluster happened on April 12 and consisted of eight events with depths of $0.5-5.5 \mathrm{~km}$. The third and final pulse of activity occurred on May 15 and consisted of fourteen events with depths of 6-10 km. Each one of these successions delineated their own individual feature. The first succession of events delineated a northeast/south west trending feature, while the latter two successions both trend east/west. All three features plunge to the east. The waveforms of this swarm showed clear P and S-wave arrivals and each individual succession's waveforms were highly similar and showed clear P and S-wave arrivals. Dominant frequencies of the April episodes were between $3-15 \mathrm{~Hz}$ with the highest amplitudes near 4 and $10 \mathrm{~Hz}$. Frequencies were slightly higher in the May episode.

\subsubsection{Bumpy Point}

The region southeast of Bumpy Point was seismically silent over the interval for which the data were examined until the 2008 mainshock-aftershock sequence (cluster 3 in Figure 18). The majority of activity in cluster 3 occurred two months after the M6.6 mainshock, in late July 
2008. The events that make up cluster 3 are all shallow, $<6 \mathrm{~km}$, and form a structure which loosely parallels the 2008 activity below Rough Bay and Cape Sudak, and plunges to the north. The waveforms that make up this July 2008 cluster were unavailable for analysis; therefore, they could not be spectrally analyzed or cross-correlated.

Unrest in the Bumpy Point region began again in late May of 2009 with a two month long mainshock-aftershock sequence. On May 29, 2009 a M4.0 mainshock earthquake occurred at a depth of $2.68 \mathrm{~km}$ and triggered more than 80 aftershocks through July 28 (Figure 16). This sequence occurred beneath the coastline $5 \mathrm{~km}$ northeast of Takawangha. The events were tightly clustered with more than 60 highly similar waveforms with clear P and S-wave arrivals. They delineate a feature which trends 350 degrees and plunges to the north. Depths of this swarm ranged from $0.4 \mathrm{~km}$ in the south to $8 \mathrm{~km}$ in the north. The dominant frequency range was between $5-18 \mathrm{~Hz}$ with strong signals near 6, 8, and $11 \mathrm{~Hz}$.

\subsubsection{Gusty Bay}

Gusty Bay exhibited isolated seismicity throughout the dataset, including two >M2.5 events during the 2008 sequence. A swarm of $300+$ high frequency events took place here beginning January 23,2017 . This swarm was centered on the coastline $10 \mathrm{~km}$ east of Takawangha, beneath Gusty Bay (Figure 19). The swarm took place 1-7 km deep along an east-west striking plane which dips to the north. Activity began on January 23 , with the occurrence of 34 tightly clustered events about $5 \mathrm{~km}$ below the coastline. The swarm peaked the following day with 150 events centered in the same location but extending slightly in each direction. Activity began to decrease over the next few days with 40, 28, and 18 events on the following three days; all the events occurred in the same location, however slightly less clustered than before. Most waveforms for this swarm showed clear P and S-arrivals, however 
only 15 events were highly similar. The dominant frequencies were between $3-13 \mathrm{~Hz}$, with the strongest signal at $7 \mathrm{~Hz}$. Several events which occurred 1-3 km deep showed slightly lower frequencies with indistinct S-waves and spectra dominated by frequencies $<5 \mathrm{~Hz}$.
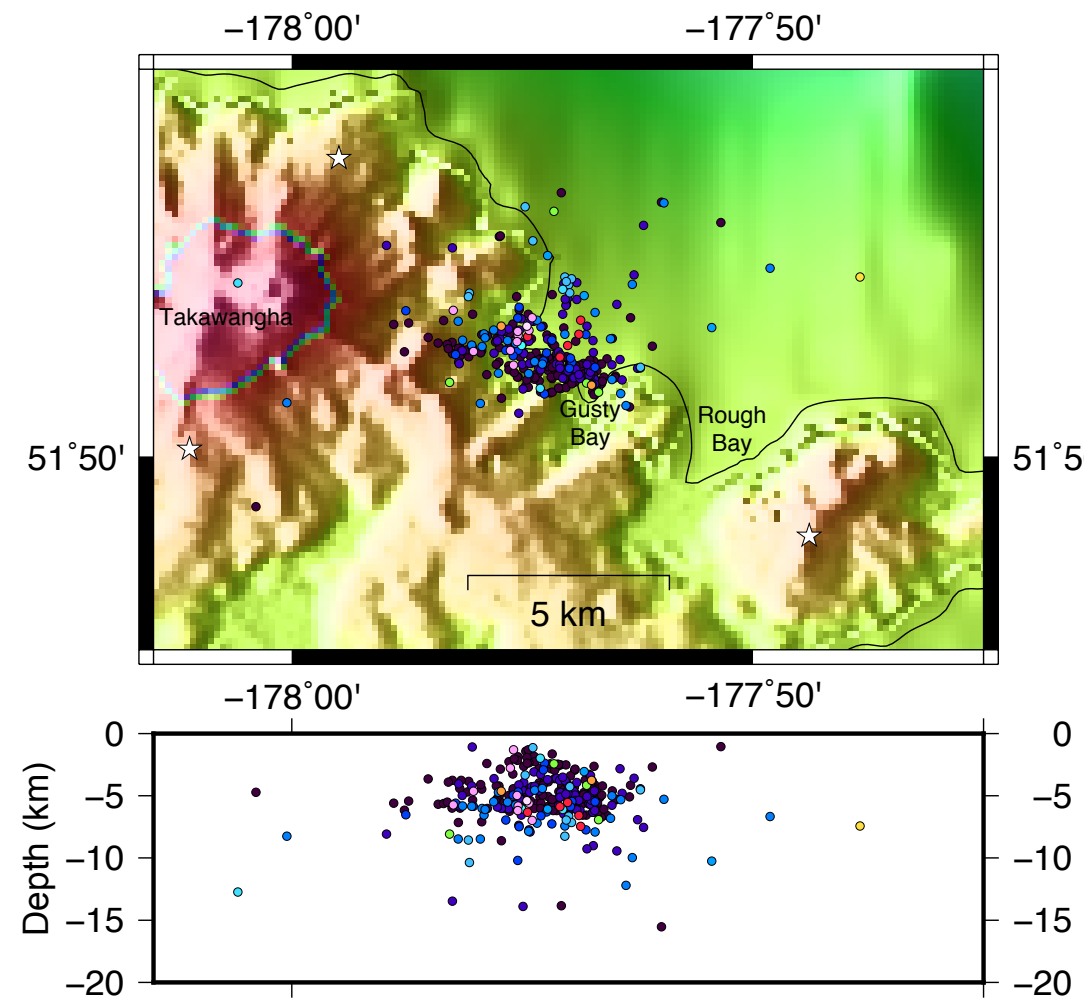

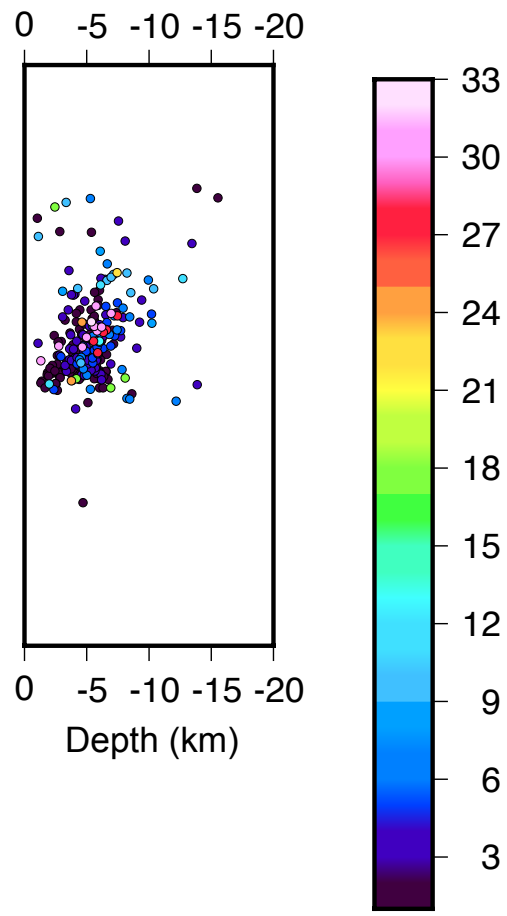

Days from January 22

Figure 19: Map of Tanaga Island, Alaska showing the January, 2017 seismic swarm. White stars are seismic stations. Colored dots are hypocenters, colored by the number of days from January 22. Depths (in $\mathrm{km}$ ) of hypocenters within the map area are projected below and to the right of the map on a E-W plane (looking north), and on a N-S plane (looking west).

\subsubsection{Western coastline of Tanaga Bay}

The western portion of Tanaga Bay is another location which has frequent isolated events throughout the dataset, including two small swarms which took place in the west portion of the bay in 2013 and 2014. A swarm of 31 events occurred in the second half of January, 2013 (Figure 16). This seismicity was tightly clustered about $9 \mathrm{~km}$ south-southeast of Takawangha with depths between $7-12 \mathrm{~km}$. This cluster delineates a structure that trends at an 
azimuth of 48 degrees and plunges southwest. Waveforms showed clear P and S-wave arrivals. Eight high frequency events from January 17-21 were highly similar with clear P and Swave arrivals; dominant frequencies were between $4-15 \mathrm{~Hz}$ with the strongest signals at 6 and $11 \mathrm{~Hz}$. Fourteen high frequency events from January 21-22 (including three later events in February and March) were also highly similar with clear P-waves and indistinct S-wave arrivals; dominant frequencies were between $4-18 \mathrm{~Hz}$ and strong signals at 7 and $12 \mathrm{~Hz}$.

A year after the 2013 swarm, seismic unrest reoccurred below the Tanaga Bay coastline, due south of Takawangha (Figure 16). Activity began January 1 and lasted until March 23. Over this time, 71 events occurred; 54 events clustered $9 \mathrm{~km}$ due south of Takawangha and 17 events clustered $2 \mathrm{~km}$ northeast of the others. The 17 events of the northeast cluster all took place on March 4. The northeastern cluster occurred at 7-8 km depth and the other 54 events clustered with depths between 6-11 km. Together these two clusters delineated a nearly horizontal structure which trends at an azimuth of 51 degrees. Individually, the waveforms the two clusters show high similarity. Both showed clear P-wave arrivals with less distinct S-wave arrivals. Sixteen highly similar events of the larger cluster showed dominant frequencies between $5-18 \mathrm{~Hz}$ with well-defined peaks at $7 \mathrm{~Hz}$. Eight highly similar events of the smaller cluster showed similar energies. This swarm showed higher amplitudes of lower frequencies $(<5 \mathrm{~Hz})$ at nearby station, TASE.

\subsubsection{South of Tanaga Island near the northern boundary of Delarof block}

The northern boundary of the Delarof forearc crustal block (as proposed by Geist et al., 1988) showed many isolated events throughout the dataset, as well as heightened seismic activity in 2005, 2010, and 2016 (Figure 9). The offshore swarms of heightened seismicity were located $>25 \mathrm{~km}$ southwest of Tanaga and had depths between 1-13 km. 16 of the 22 events 
from the 2010 cluster had highly similar waveforms and dominant spectra between 3-15 Hz. Waveforms of this cluster showed clear P-wave arrivals often with indistinct S-wave arrivals. The waveforms from the 2005 and 2016 clusters showed similar energies to those of the 2010 cluster. The 2016 activity roughly trends north-south, perpendicular to the northern boundary of the Delarof Block.

\section{Discussion:}

Seismic activity near Tanaga Island may be broadly grouped into two categories: those associated with volcanic activity and those caused by tectonic stresses. Our analysis shows that, contrary to expectations, Takawangha is much more seismically active than the other three volcanoes on Tanaga Island. We identify VT, hybrid, and LP events associated with Takawangha during both the October 2005 and July 2006 swarm episodes. Seismic activity beneath the WTVC was relatively quiet and sparse throughout the dataset.

Tectonic stress in the Andreanof region is generated by the high convergence rate and oblique convergence angle with regional plate coupling at the subduction zone. A portion of the resulting shear strain is accommodated by seismicity on the boundaries of rotating forearc crustal blocks and left-lateral strike-slip fault in the volcanic arc transect. In this analysis, we identify tectonic seismicity associated with both of the previously stated deformation processes.

Geist et al. (1988) suggest that the clockwise rotation of crustal blocks in the forearc create triangular-shaped basins in the extensional corners between the rotating blocks and the unroated arc massif. Although there are no large basins near the northern boundary of the Delarof block, Geist et al. (1988) propose the possibility of basins near Tanaga and Kanaga Islands that have since filled in by volcanic debris. In addition, numerous transverse canyons cutting into the southern margin of the Delarof block indicate it may be segmented into many 
smaller sub-blocks (Geist et al., 1988). It's important to note that the block boundaries proposed by Geist et al. (1988) are largely idealized and based mainly on the basis of geomorphic evidence and seismic reflection data.

Similar to the Central Aleutians, arc-normal strike-slip faulting is also observed in Nicaragua (La Femina et al., 2002). In Nicaragua, these faults are thought to accommodate translation in the volcanic arc. Additionally, M6+ events are observed on these Nicaraguan faults about 150 miles from the trench. La Femina et al. (2002) interprets this as bookshelf faulting. Bookshelf faulting is a type of Riedel shear usually arranged en echelon (resembling the kinematics of a tilting row of books on a shelf; Dresen, 1991). In subduction settings, these faults often strike 10-30 degrees from the relative plate motion vector's azimuth (Jackson, 1997). The cause for similar faults in the Andreanof region is likely due to the stresses caused by the northwestward translation of the region. Cross and Freymueller (2007) model plate coupling in the Andreanof region using GPS observations. Their model suggests that the northwest translation of the western Andreanof region results from a high degree of plate coupling at the subduction zone interface below. Observations show the northwestward transport (>1 cm/yr) of the western Andreanof region, including Tanaga, at an average azimuth of 306 degrees (relative to North America).

We cannot definitively identify the causes of all Tanaga Island seismicity. Consequently, the following discussion primarily focuses on our analysis of swarm activity and mainshockaftershock sequences because together they make up nearly $60 \%$ of the local seismicity. Relocations of seismic swarm episodes and mainshock-aftershock sequences help delineate the seismic structure occurring beneath Tanaga Island. Nevertheless, the background seismicity is useful in determining which subsurface structures remain active through time. 


\subsection{Regional-tectonic seismicity}

\subsubsection{Offshore Cape Sudak}

The activity associated with the 2008 mainshock-aftershock sequence is interpreted by Ruppert et al. (2012) as shear strain partitioning due to the oblique subduction of the Pacific Plate beneath the North American Plate and the northwestward translation of the Andreanof region due to regional plate coupling. Ruppert et al. (2012) suggest that shear strain partitioning in the central Aleutians is demonstrated by arc-normal strike-slip faults in the volcanic arc and the rotation of forearc blocks which are bound by normal and strike-slip faults. Large magnitude strike-slip earthquakes, similar to the M6.6 mainshock event, are common in the central and eastern Aleutian Arc (Ruppert et al., 2012). Our relocations and spectral analysis of the mainshock and aftershocks located offshore Cape Sudak depict a nearly vertical zone of brittle failure which strikes 346 degrees, and has hypocenters located between depths of 1-12 km (Cluster 1 in Figure 20). This is consistent with moment tensors calculated by USGS; the mainshock displays a left-lateral strike-slip fault plane which strikes 170 degrees with a dip 86 degrees to the west and a M4.9 aftershock displays a similar left-lateral strike-slip fault plane which strikes 341 with a dip of 89 degrees to the east. The delineated fault or more likely system of faults is arc-normal, and lies within the volcanic arc, about $160 \mathrm{~km}$ away from the trench. Because the proposed boundaries of the Delarof block (Geist et al., 1988) are not entirely certain, it is possible that the Cape Sudak fault zone may be related to block rotation; however, no further evidence suggests that the block boundary be shifted north of the proposed location by Geist et al. (1988). Given that the location of the Cape Sudak fault zone is situated about $20 \mathrm{~km}$ north of the proposed block boundary (Figure 9), we suggest that either the defined block boundaries need refinement or that this feature is not accommodating block rotation.

Rather, the Cape Sudak fault zone may accommodate the northwestward transport of the Andreanof region, similar to La Femina et al.'s (2002) observations in Nicaragua. Our 
relocations of the Cape Sudak strike-slip fault zone trend at an azimuth of 346 degrees, oblique by only 27 degrees from the azimuth of relative plate motion (319 degrees). The 27 degree obliquity is within the commonly observed 10-30 degrees, noted by Jackson (1997), justifying there is enough evidence to link this seismicity to bookshelf faulting. Ruppert et al (2012) suggests that these arc-normal strike-slip faults may accommodate early stages of shear slip partitioning that may later transform into a single arc-parallel through-going fault.

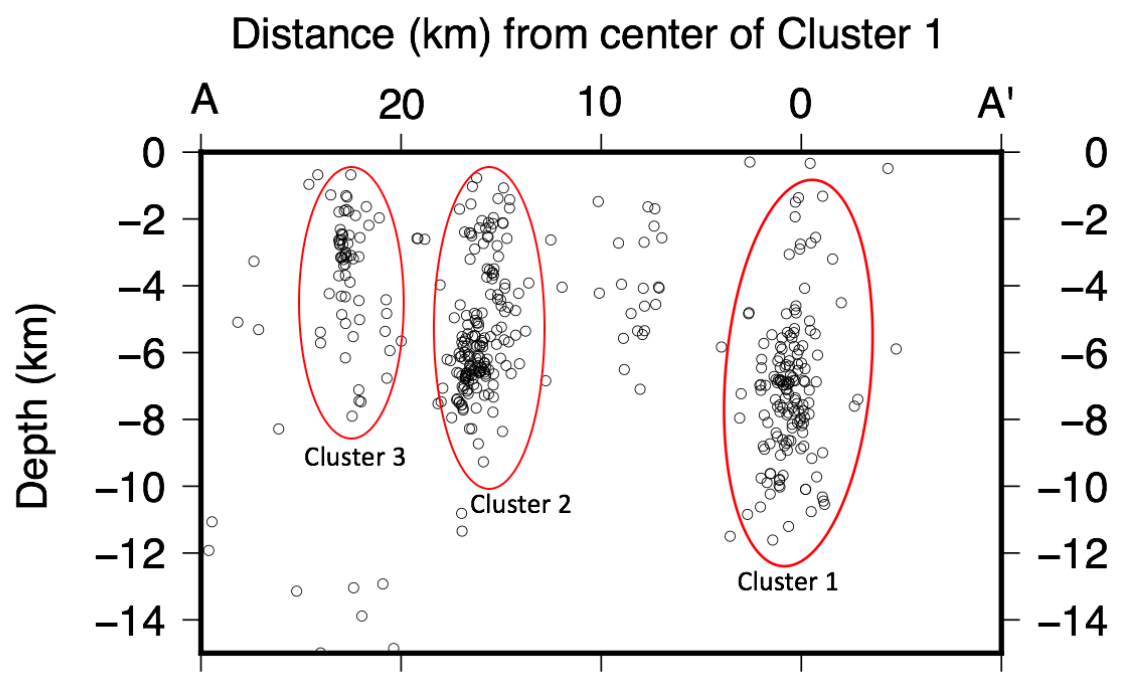

Figure 20: Cross-section A-A' (Figure 18) of the 2008 swarm. This cross-section window looks from south to north and is oriented orthogonal to the strike of Cluster 1 (A-A' azimuth is 76 degrees). Each cluster is outlined in red ellipses.

\subsubsection{Southwest offshore Tanaga}

The Delarof Block, one of five of the crustal forearc blocks proposed by Geist et al (1988), extends through the southern tip of Tanaga Island and is bounded by strike-slip and normal faults (Figure 3). Although the boundaries of this block are not definitive, our relocations show activity along the proposed northern boundary of the Delarof Block in 2006, 2010, 2013, 2016, and 2017 (Figure 9). The diffuse character of these clusters and large RMS error associated with the 2010 events could be due to the geometry of the seismic network and the large event-station distance. Because this swarm lies south of all seismic stations it is difficult to 
determine the latitudes and focal depths with high precision. Nonetheless, given the relative relocations of this activity in relation to the northern boundary of the Delarof Block and their shallow (between 1-15 km) hypocenters, this seismicity is suggested to accommodate the clockwise rotation of the Delarof crustal block via strike-slip and normal faulting.

\subsection{Volcano-tectonic seismicity}

\subsubsection{Takawangha activity}

The earthquake swarm of 2005 involved focal depth shallowing of nearly 600 events below the northern part of Tanaga Island and culminated in a several-minute long period of volcanic tremor. This swarm was composed of mainly VT events starting at depths between 12$16 \mathrm{~km}$ below the WTVC and migrating up to depths between 0-6 km below ancestral Tanaga and Takawangha. Even though there was not a verified eruption associated with the tremor signal, the possibility for one during this time remains.

Focal mechanisms for 112 events from October 2-25 2005 were provided by AVO and show a general trend of shallowing hypocenters and transition from early reverse faulting to later normal faulting. The shallowing of hypocenters (October 2-7) is mostly dominated by reverse faulting mechanisms. From October 8-25, after the initial shallowing, focal mechanisms were dominated by normal faulting.

Although the double-difference method significantly reduced the RMS error of the 2005 swarm, our relocations were comparable to the original locations. The migration of VT earthquakes likely reflect stress changes caused by the movement of volcanic gas or magma as proposed by Coombs et al. (2007a). This is supported by three pieces of seismological evidence: the observed shallowing of earthquakes during the period of unrest, the volcanic tremor recorded on October 17, and hybrid events recorded between October 10 and November 21. Lu and Dzurisin (2014) suggest that the 2005 earthquake swarm may have been caused by the pressurization of the magma chamber at depth which forced magmatic or hydrous fluid to 
migrate to shallower depths along the zone of weakness created by the edifice collapse of ancestral Tanaga. The proposed scar left behind by the edifice failure is illustrated by Coombs et al. (2007b) nearly $2 \mathrm{~km}$ west of the amphitheater ridge and projects $2 \mathrm{~km}$ below sea level as it dips west (Figure 4). Relocations do not show much activity near the proposed subsurface scar. Instead, hypocenters shallow just east of the scar, directly beneath the amphitheater ridge and on the west flank of Takawangha. The hydrothermally altered rocks and conduit breccias exposed along the steep walls of this ridge suggest it may be the eroded remains of ancestral Tanaga's volcanic center (Jicha et al., 2012). If true, pressurization of a magma reservoir $\sim 15$ $\mathrm{km}$ below sea level on October 2-6 may have caused magmatic or hydrothermal fluid to change the local stress regimes and bring about brittle failure which shallowed on October 7-13 along the weakened hydrothermally altered rocks below the amphitheater ridge.

Further evidence for the pressurization of a magma chamber at depth is supported by InSAR imagery analyzed by Lu and Dzurisin (2014). Their observations showed broad surface inflation of 3-5 cm between September 10 and October 15, 2005, spanning the time period of the swarm. The fringe pattern is elongated in the northwest/southeast direction, includes all 4 volcanic centers, and is centered beneath the amphitheater ridge (Figure 21). Lu and Dzurisin (2014) attributed the broad surface uplift to magma intrusion at depth. They argue for an intrusion of magma because activity begins at depths between 11-18 $\mathrm{km}$, too deep for hydrothermal fluids (Fournier, 2007). Lu and Dzurisin estimated a volume change of the source between $0.002-0.008 \mathrm{~km}^{3}$, based on two models: a best-fit spherical pressure (Mogi) source and an ellipsoid source (Figure 22). These two models are each embedded in a homogeneous host rock with reasonable elastic properties. Lu and Dzurisin were unable to choose a preferred model between the two, however the ellipsoid source model results seemed to better replicate the observed elongated pattern. The best-fit for the ellipsoid source is a shallow-dipping (northwest) prolate spheroid source located 3-9 km below sea level between Tanaga and 
Takawangha. For this model, Lu and Dzurisin (2014) propose a single large magma body with separate conduits extending toward the surface to feed each volcano. This is consistent with the geochemistry work of Jicha et al. (2012), who suggest that the volcanoes on Tanaga Island may share parent magmas of similar composition, and that Tanaga and East Tanaga plagioclasepoor magmas crystalize at greater depths than the plagioclase-dominated Takawangha magmas. Lu and Dzurisin's best-fit ellipsoid source model adheres to the results in Jicha et al. (2012) that are interpreted to be due to individual conduits that source magma at different depths of the proposed, dipping magma reservoir. Our results are consistent with this model. It is important to note that the illustrated cross-section of the proposed Tanaga plumbing system from Lu and Dzurisin (2014; Figure 22) ends near $10 \mathrm{~km}$ below sea level and shows an inferred feeding conduit (into the magma reservoir) directly below the amphitheater ridge; this does not fully explain the VT events which occurred at depths between 12-16 km from October 1-6 below Tanaga Volcano. Given the hypocenter locations of these earlier VT events, we suggest that there may be either a separate conduit feeding into the proposed magma reservoir or that the one depicted by Lu and Dzurisin (2014) be shifted westward 4-5 km below Tanaga. 
(a) V373:20050910-20051015

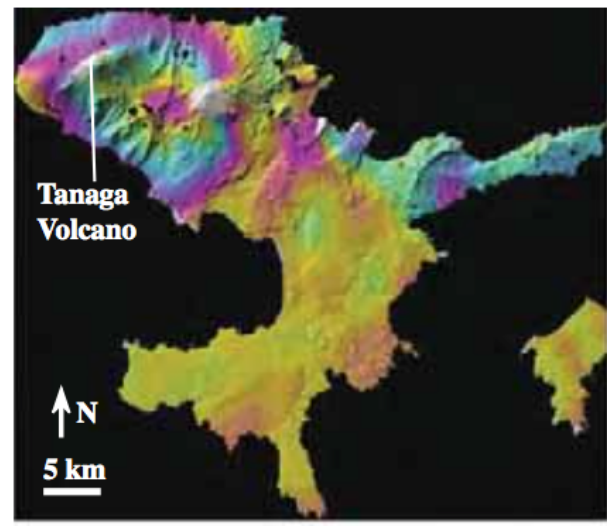

(c) V144:20051103-20060706

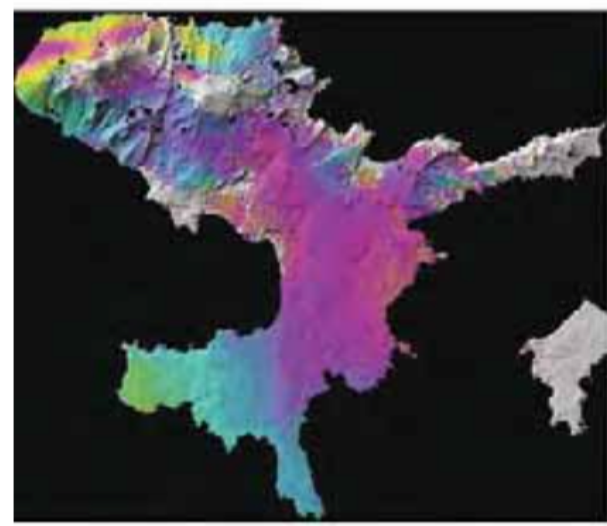

(e) V022:20040901-20060906

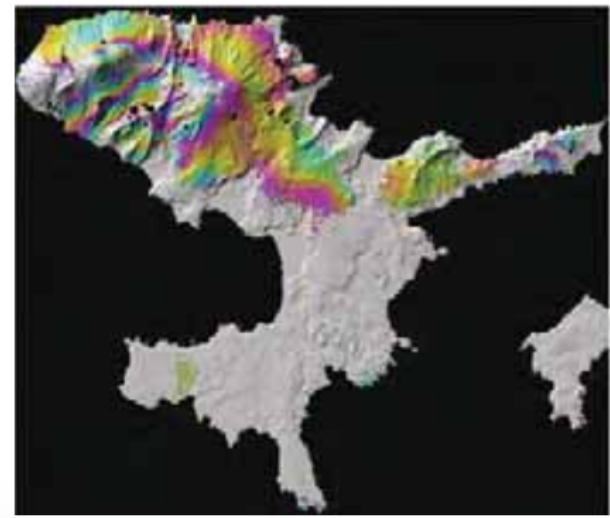

(b) V373:20050702-20060826

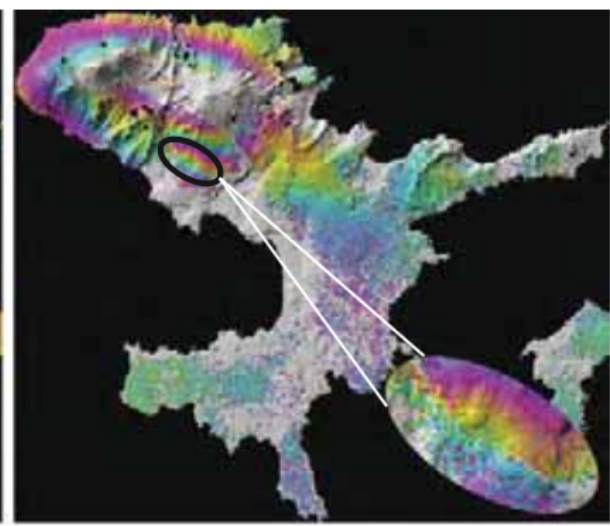

(d) V144:20050825-20051103

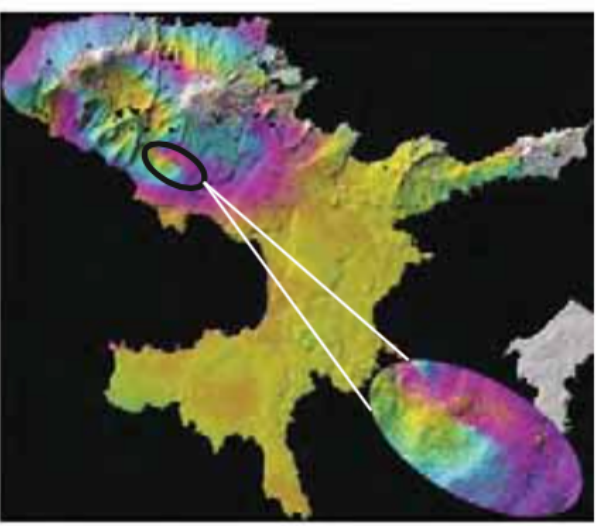

(f) V144:20050825-20060810

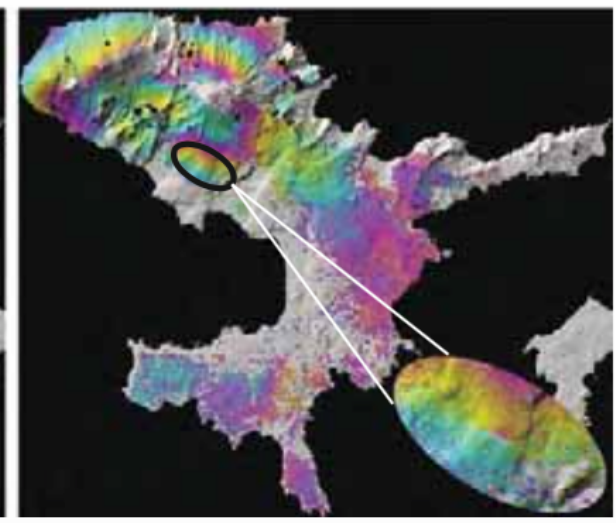

Figure 21: Observed InSAR images of Tanaga Island (courtesy of Lu and Dzurisin, 2014) for the following time periods: a.) September 10, 2005-October 15, 2005, b.) July 2, 2005-August 26, 2006, c.) November 3, 2005-July 6, 2006, d.) August 25, 2005-November 3, 2005, e.) September 1, 2004-September 6, 2006, and f.) August 25, 2005-August 10, 2006. The elongated fringe pattern is visible in all images except (c) which spans an 8-month period following the peak of the swarm. Lu and Dzurisin suggest the anomalous region of localized deformation outlined in black ellipses in (b), (d), and (f) may correspond to the October 17, 2005 tremor signal. A full cycle of colors (i.e., one interferometric fringe) represents $2.83 \mathrm{~cm}$ of surface displacement along the satellite-to-ground line of sight. 


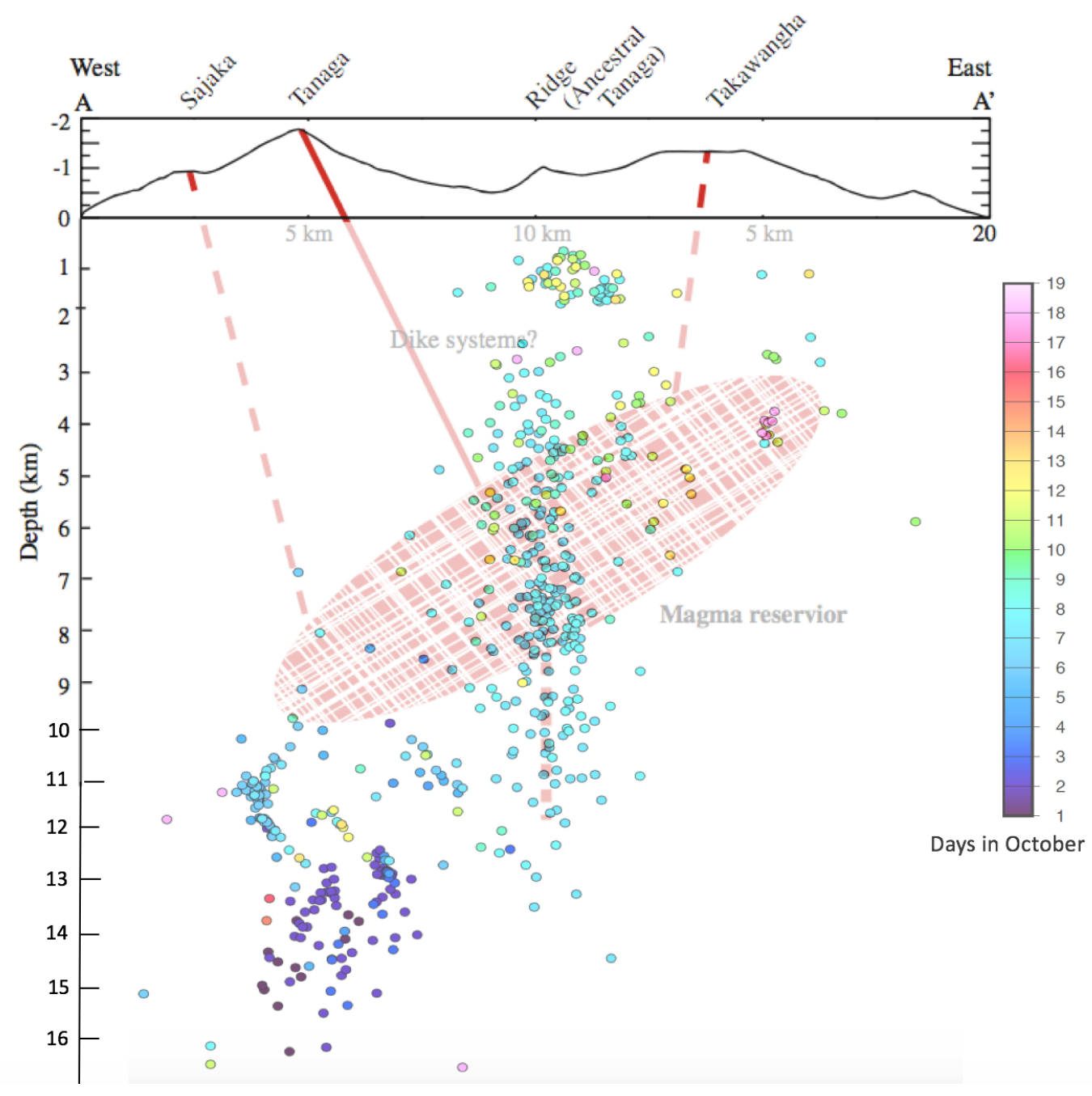

Figure 22: Cross section of Tanaga Island, Alaska modified from Lu and Dzurisin (2014), showing their best fit ellipsoid source model to explain the observed surface inflation. Hypocenter relocations from the 2005 swarm are shown in colored dots. Pink dots indicate hypocenters from November 2005.

After the period of shallowing hypocenters between October 2-9, the daily rate of earthquakes decreased and stations nearest Takawangha record an eight-minute-long volcanic tremor signal. McGimsey et al. (2007) postulate this signal may have been caused by a landslide or small phreatic explosion, but no activity was verified via satellite imagery. Based on the harmonic spectrum throughout the signal, we favor the model of a phreatic blast, as landsliding does not generate harmonic seismicity (Allstadt et al., 2018). 
The physical mechanisms causing volcanic tremor remain weakly understood. Kontantinou and Schlindwein (2002) suggest several models including: 1) fluid-flow-induced oscillations of conduits; 2) resonance of fluid dilled cracks; 3) bubble growth/collapse of boiling ground water; 4) oscillations due to the different geometries of magma bodies. Tremor is also often observed preceding phreatic and phreatomagmatic eruptions (McNutt and Nishimura, 2008). Our observations are consistent with the idea that this signal represents volcanically related fluid movement; however, with the available evidence, we are unable to definitely determine the physical mechanism causing the tremor on October 17, 2005.

InSAR imagery shows localized surface displacement about $4 \mathrm{~km}$ south of Takawangha between October 15 and November 3, 2005 (black ellipsoids in Figure 21). As suggested by Lu and Dzurisin, it is possible that this displacement could be attributed to the October 17 tremor event. Seismic station TAFP is located northeast of the proposed source, so P-wave particle motions would be oriented in that direction. Instead we calculated a north-south particle motion (Figure 15) vector at TAFP. Rather than pointing toward the InSAR source region, this points toward the cluster of hybrid events observed on November 20, southeast of Takawangha. Furthermore, the location of the localized deformation is nearly equidistant to both TAFP and TACS, however, the signal clearly arrives nearly 40 seconds earlier at TAFP (reference Figure 1 for station locations). This offset could be attributed to the difference in physical properties along the ray path. Because the tremor signal arrived first at TASE and $<10$ seconds later at TAFP with a first motion vector that points directly south of TAFP; we suggest that this tremor was associated with Takawangha fluid migration near the events which occurred on November 20 (pink cluster southeast of Takawangha in Figure 11), instead of the site of the anomalous fringe location.

Another small earthquake swarm in July/August 2006 sheds further insight on the anomalous site of localized surface deformation south of Takawangha (Figure 16). This cluster includes 27 high frequency VT events including at least four hybrid events which gives 
indication of shallow near surface faulting $(<2 \mathrm{~km})$ and fluid migration on the south flank of Takawangha. Analogous to the 2005 swarm, these VT and hybrid events were accompanied by four events 7-15 km below the north/northwest flank of Tanaga Volcano. Although the cause of the localized surface deformation is unclear between October 15 and November 3, 2005, this swarm illustrates that shallow faults exist below which have the potential to trigger landslides and/or surface deformation. Furthermore, the hybrid events observed with this swarm indicate fluid movement at shallow depths and the potential of phreatic eruptions and/or venting at the surface.

\subsubsection{WTVC activity (Tanaga, East Tanaga, and Sajaka)}

Excluding the early VT events of the 2005 swarm, no swarm seismicity occurred below the WTVC. Most seismicity below the WTVC occurred as isolated events often days, months, or years apart. We observed 47 VT and 5 hybrid events below the volcanic cluster (Figure 16). Due to the timing of four VT events below Tanaga and the shallow Takawangha swarm in 2006 (Figure 17), we suggest the four deep events may be associated with shallow brittle failure and fluid movement $4 \mathrm{~km}$ south of Takawangha, comparable to the 2005 swarm. The majority of the other 43 VT events cluster between 4-8 km beneath Tanaga Volcano. The five hybrid events in 2015 suggest brittle rupture accompanied by fluid movement $5 \mathrm{~km}$ south of Tanaga at depths between 4-6 km. The observation of VT and hybrid events below this volcanic cluster affirms that the volcanic stresses of Tanaga, East Tanaga, and Sajaka continue to cause brittle failures on underlying faults. 


\subsubsection{Summary of volcanic seismicity}

All four of the volcanoes on Tanaga Island have been seismically active since 2003 . Takawangha proves to be the most seismically active, whereas Sajaka, Tanaga and East Tanaga appear more quiet. This is an important result, as Takawangha proves to be more seismically active even though magmatic activity was thought to have shifted away from Takawangha and toward the Tanaga cluster $19 \mathrm{ka}$ (Jicha et al., 2012). Tanaga is the second

most seismically active, followed by Sajaka and East Tanaga; all three of these volcanoes show weak signs of brittle rupture. The 2015 hybrids on the south flank of Tanaga hint at fluid movement 4-6 km below the surface. In addition, the observed low frequencies recorded near Takawangha in 2005 and 2006 display evidence of volcanically related fluid movement. This suggests that Takawangha may represent an underappreciated hazard.

\subsection{Uncategorized seismicity}

\subsubsection{Southeast of Bumpy Point}

The location of the 2008 (cluster 3) and 2009 clusters that lie beneath the coastline near Bumpy Point was quiet until July 2008. The 2008 activity delineated a north-south trending feature plunging steeply to the north. This same fault zone was reactivated in 2009 by a M4.0 mainshock, and a longer portion of it (about $2 \mathrm{~km}$ further north and slightly deeper) exhibited activity. Analogous to the 2008 sequence, the 2009 unrest was accompanied by four events in the Cape Sudak fault zone. This fault zone parallels the feature east of Cape Sudak (Figure 18 and 20) thought to be associated with the release of tectonic stress via bookshelf faulting and may represent another en echelon bookshelf fault. 


\subsubsection{Rough Bay and Gusty Bay}

The region beneath Gusty Bay and offshore Rough Bay was seismically active in 2004 contemporaneous with the 2008 M6.6 event. Although portions of this area were active earlier than 2008, we invoke trigging for the 2008 cluster 2 due to the coincident increase in seismicity immediately ( $<1$ hour) following the mainshock. This included three $M>2.5$ events in Gusty Bay and more than ten in the cluster offshore Rough Bay (Figure 18). The 2008 activity offshore Rough Bay delineated a nearly vertical zone of faults loosely trending 348 degrees with depths ranging from 1-9 km (Figure 20). In 2010, the northern portion of this cluster reactivated along a sub-vertical fault between $3-8 \mathrm{~km}$ deep. In 2011, the southern portion of this cluster reactivated along two or possibly three separate sub-vertical faults. The activity in Rough Bay parallels the faults discussed prior near Bumpy Point and offshore Cape Sudak (Figures 18 and 20). It is possible that this activity represents yet another en echelon bookshelf fault accommodating northwestward translation of the Andreanof region. The three LP events observed in Rough Bay are the only LP events in our dataset. The presence of these LP's indicate fluid movement about $5.5 \mathrm{~km}$ below the surface, in a location with no obvious connection to the nearest volcano, Takawangha.

The three $M>2.5$ events in 2008 beneath Gusty Bay indicate a fault zone $5 \mathrm{~km}$ below the surface. In 2017, 300 VT events occurred along the same fault zone. As the 2017 swarm grew larger, brittle failure spread in every direction. It is difficult to delineate the plexus of faults which exist here, for this cluster is large and very dense; however, brittle failure was observed mainly on a plane which strikes 279 and dips to the north. Furthermore, the cause of the Gusty Bay cluster remains unclear. Because portions of this area were moderately active in 2004 and then quiet until triggered by the 2008 mainshock, it is possibly that these crustal faults further accommodate a portion of the northwestward translation via normal and/or strike-slip faulting. 
This could be investigated further by determining focal mechanisms for events within these clusters.

\subsubsection{West Tanaga Bay ( $8 \mathrm{~km}$ south of Takawangha)}

In 2013 and 2014, heightened seismicity $8 \mathrm{~km}$ south of Takawangha showed signs of brittle rupture at depths between $6-10 \mathrm{~km}$. These two clusters both trend at azimuths near 50 degrees, roughly in-line with seismicity north of Cape Sudak and Rough Bay. This suggests that the 2013 and 2014 clusters may represent the release of tectonic stress. If true, these features would likely be normal faults accommodating the northwest translation as they are oriented nearly perpendicular to the Andreanof region motion vector.

\subsubsection{Southeast $(25 \mathrm{~km})$ of Takawangha}

The events from January 2006 delineate two faults that trend 346 and 340 degrees plunge to the south between $5-10 \mathrm{~km}$. This swarm occurred in two episodes 11 days apart; the latter feature of this swarm is one km east and may indicate a splay from the fault that had just failed earlier in January. This same location was again active during the 2008 mainshockaftershock sequence. Additionally, this swarm parallels the 2008 Cape Sudak fault zone and is situated in-line with the cluster near Bumpy Point active in 2008 and 2009 (Figure 17). Although the 2006 and 2009 swarms show opposite plunges, it may be possible that they lie on a single through-going fault. Because this activity parallels the Cape Sudak fault zone and was also active during the 2008 sequence, it may suggest that this zone of brittle rupture in 2006 is similarly related to trench-normal, en echelon bookshelf faulting. 


\section{Conclusion}

This study utilizes the seismic record from 2003-2017 to identify subsurface fault structures related to volcanism and crustal tectonics in the Aleutian volcanic arc near Tanaga Island. Using both catalog arrival times and cross-correlated adjusted arrival times, we relocate hypocenters with high precision using the HypoDD double-difference method. We examine the spatial relationships and spectral diversity of swarm episodes and mainshock-aftershock sequences to determine zones of brittle failure and fluid movement below the Tanaga region. We concluded that all four volcanic centers have exhibited seismic activity since 2003. VT seismicity associated with Tanaga, East Tanaga, and Sajaka was relatively sparse and limited to $<50$ events from 2006-2015. Five hybrid events on the south flank of Tanaga indicates brittle rupture accompanied by fluid movement in 2015. Although Takawangha exhibits similar background seismicity to the other three volcanoes, the 2005 and 2006 volcanic swarms associated with Takawangha confirm that it is far more seismically active. For the October 2005 period of unrest, we identify VT, hybrid, and LP events and suggest their relationship to shallow injection of magma and/or associated fluids, and the subsequent stress changes due to pressurization and lubrication of faults via hydrothermal fluids. This conclusion supports the findings of Lu and Dzurisin (2014), and is consistent with their proposed magma chamber 3-8 $\mathrm{km}$ below ancestral Tanaga. Furthermore, our results prove that Takawangha is the most seismically active of the TVC in spite of the suggestion that magmatic activity shifted away from Takawangha $19 \mathrm{ka}$ (Jicha et al., 2012). We resolve shallow faults south of Takawangha in 2006, 2013, and 2014. The 2006 VT and hybrid events are $<2 \mathrm{~km}$ below the south flank of Takawangha and may demonstrate the possible causes for localized surface deformation.

Seismicity related to the release of tectonic stress in the Tanaga region originates from the oblique convergence angle and regional plate coupling at the subduction zone (Ruppert et al., 2012; Cross and Freymueller, 2007). We identify seismicity which accommodates a portion 
of the resulting shear strain along arc-normal strike-slip faults in the volcanic arc transect and clockwise-rotating crustal blocks in the forearc. The 2008 mainshock-aftershock sequence delineates a left-lateral strike-slip fault zone just east of Cape Sudak which trends 346 degrees extends for nearly $25 \mathrm{~km}$ (Figure 18). Similar arc-normal faulting is common in the central and eastern Aleutian arc and is suggested to represent bookshelf faulting (Ruppert et al., 2012). The fault zone east of Cape Sudak likely accommodates the northwestward translation of the western Andreanof region which is generated by a high degree of plate coupling at the subduction interface below. We suggest three other fault zones that parallel the Cape Sudak activity and may accommodate the northwestward translation via en echelon faulting. We speculate that seismicity was triggered at the Rough Bay fault zone based on the timing of unrest immediately following the 2008 mainshock event. Background (non-swarm) seismicity indicates that the previously mentioned fault zones continue to remain active. In addition, we identified seismicity likely accommodating the clockwise rotation of the Delarof forearc block via strike-slip and/or normal faulting. The Delarof crustal block is one of five forearc blocks proposed by Geist et al. (1988) along the central and eastern Aleutian Arc resulting from the oblique convergence angle. Relocated seismicity shows activity along the northern boundary of the Delarof block from 2005-2017 which includes a small swarm episode in 2010.

This study interprets seismic activity sourced from both volcanic and tectonic stresses in the Tanaga region. Although we suggest possible sources for most of the seismicity, there are still locations where we are unable to definitively classify the seismic sources. Continued monitoring of Tanaga seismicity along with further research to generate focal mechanisms would aid in better understanding the seismicity in the Tanaga region and how it relates to the volcanic and tectonic stresses. 


\section{References}

Allstadt, K. E., Matoza, R. S., Lockhart, A. B., Moran, S. C., Caplan-Auerbach, J., Haney, M. M., Thelen, W. A., Malone, S. D., 2018, Seismic and acoustic signatures of surficial mass movements at volcanoes: Journal of Volcanology and Geothermal Research, vol. 364, p. 76-106

Chouet, B.A., 2003, Volcano Seismology: Pure and Applied Geophysics, vol. 160, p. 739-788

Coats, R. R., and Marsh, B. D., 1984, Reconnaissance geology and petrology of northern Tanaga, Aleutian Islands, Alaska: Abstracts with Programs - Geological Society of America, vol. 16, n. 6, p. 474.

Coats, R. R., 1950, Volcanic activity in the Aleutian Arc: U.S. Geological Survey Bulletin (B 0974-B), p. 35-49

Coombs, M. L., McGimsey, R. G., and Browne, B.L., 2007a, Preliminary Volcano-Hazard Assessment for the Tanaga Volcanic Cluster, Tanaga Island, Alaska: USGS Scientific Publications Report 3007-5094

Coombs, M. L., White, S. M., and Scholl, D. W., 2007b, Massive edifice failure at Aleutian arc volcanoes: Earth and Planetary Science Letters, vol. 256, p. 403-418

Cross, R.S., Freymueller, J.T., 2007. Plate coupling variation and block translation in the Andreanof segment of the Aleutian arc determined by subduction zone modeling using GPS data: Geophysical Research Letters, v. 34

Dixon, J.P., Stihler, S.D., Power, J.A., Tytgat, G., Estes, S., and McNutt, S.R., 2006, Catalog of Earthquake Hypo- centers at Alaskan Volcanoes: January 1 through December 31, 2005: U.S. Geological Survey Open-File Report 2006-1264

Drezen, G., 1991. Stress distribution and the orientation of Riedel shears: Tectonophysics 188, 239-247.

Ekström, G., M. Nettles, and A. M. Dziewonski, 2012, The global CMT project 20042010: Centroid-moment tensors for 13,017 earthquakes: Physical Earth Planet. Inter., vol. 200201 , p. $1-9$

Fournier, R. O., 2007, Hydrothermal systems and volcano geochemistry: Volcano deformation, p. 323-341

La Femina, P.C.L., Dixon, T., and Strauch, W., 2002, Bookshelf faulting in Nicaragua: Geology, v. 30, p. 751-754

Geist, E. L., Childs, J. R., Scholl, D. W., 1988, The origin of summit basins of the Aleutian Ridge: implications for block rotation of an arc massif: Tectonics, vol. 7, p. 327-341.

Jackson, J.A. (Ed.), 1997. Glossary of Geology, 4th ed. American Geological Institute, Alexandria, Virginia. 
Jicha, B. R., Coombs, M. L., Calvert, A. T., and Singer, B. S., 2012, Geology and 40Ar/39Ar geochronology of the medium-to high-K Tanaga volcanic cluster, western Aleutians: Geological Society of America Bulletin, vol. 124(5-6), p. 842-856

Klein, F. W., 2002, User's guide to HYPOINVERSE-2000, a Fortran program to solve for earthquake locations and magnitudes: US Geological Survey, No. 02-171

Lahr, J.C., Chouet, B.A., Stephens, C.D., Power, J.A., and Page, R.A., 1994, Earthquake classification, location, and error analysis in a volcanic environment: implications for the magmatic system of the 1989-1990 erupptions at Redoubt Volcano, Alaska: Journal of Volcanology and Geothermal Research, vol. 62, p. 137-151

Lahr, J.C., 1999, HYPOELLIPSE: a computer program for determining local earthquake hypocentral parameters, magnitude, and first-motion pattern: U.S. Geological Survey Open-File Report 99-23, version 1.1, p. 119

Lu, Z., and Dzurisin, D., 2014, InSAR Imaging of Aleutian Volcanoes: Chichester, UK, Springer Berlin Heidelberg

McNutt, S. R., 2005, Volcanic Seismology: Annual Review of Earth and Planetary Sciences, vol. 33, p. 15.1-15.31

McNutt, S. R., and Nishimura, T., 2008, Volcanic tremor during eruptions: temporal characteristics, scaling and constraints on conduit size and processes: Journal of Volcanology and Geothermal Research, vol. 178, p. 10-18

Mortera-Gutierrez, C. A., Scholl, D. W., and Carlson, R. L., 2003, Fault trends on the seaward slope of the Aleutian Trench: Implications for a laterally changing stress field tied to a westward increase in oblique convergence: Journal of Geophysical Research, vol. 108, No. B10

Paige, C. C., and Saunders M. A., 1982, LSQR: Sparse linear equations and least squares problems: ACM Transactions on Mathematical Soft- ware, p. 195-209.

Power, J. A., Stihler, S. D., White, R. A., and Moran, S. C., 2004, Observations of deep long-period (DLP) seismic events beneath Aleutian arc volcanoes; 1989-2002: Journal of Volcanology and Geothermal Research, vol. 138.3, p. 243-266

Reyes, C. G. and West, M. E., 2011. The Waveform Suite: A Robust Platform for Manipulating Waveforms in MATLAB: Seismological Research Letters, vol. 82, p. 104-110

Ruppert, N.A., Kozyreva, N.P., and Hansen, R.A., 2012, Review of crustal seismicity in the Aleutian Arc and implications for arc deformation: Tectonophysics, v. 522-523, p. 150-157

Waldhauser, F., and Ellsworth, W. L., 2000, A double-difference earthquake location algorithm: Method and application to the northern Hayward fault, California: Bulletin of the Seismological Society of America, vol. 90.6, p. 1353-1368 
7. Appendix

Below we include a more detailed step-by-step procedure of our methods, a map of the original catalog locations, and a catalog of all events relocated in this study.

7.1 Detailed methods procedure

1. Catalog locations in hypoellipse and hypoinverse format and waveform files in SAC format were provided by AVO.

2. Hypoellipse and hypoinverse files were converted into phase files using hypoe2pha and ncsn2pha scripts which are included in the HypoDD package.

3. Dr. Peng's code requires that original pick times must be found within the header of waveform (SAC) files. For that reason, a python script (section 7.2.1) was created to match events from phase files to the corresponding waveform directories. This script creates two files: 1. matched.pha - a phase file of events only which had a corresponding waveform and 2. evid_tempid.list - a matched list of event ID's and the corresponding waveform directories.

4. An additional MATLAB script, SAC.add_pick (section 7.2.2) was created to take travel times from the phase file and write those times into the SAC waveform header for each available station.

5. After the waveform headers were amended, they were cross-correlated using Dr. Zhigang Peng's Waveform_cross_correlation Package to get a dt.cc file. This output file contains travel time differences for events with similar waveforms at available stations.

6. Catalog phase files and a stations location file where used as inputs for ph2dt to get individual dt.ct output files. These files contain travel time differences for two neighboring events at available stations. In addition, ph2dt creates an event list as an output.

7. HypoDD requires dt.cc, dt.ct, stations list, and event list files as inputs. It outputs relocations (section 3), original locations, and a log file.

8. Original locations and relocations are then mapped using scripts created for GMT.

9. Waveforms were cross-correlated and examined spectrally using the GISMO toolbox in MATLAB. 


\subsection{Scripts}

7.2.1 Python script (match-pha-timestamp-to-waveform-directory.py) created by Jim Long.

\#!/usr/bin/env python2.7

\# We'll read a .pha file of earthquake event data, looking only at the

\# lines that begin with a pound sign, which indicate the date and time

\# of a seismic event.

\# For each event found, we will attempt to match the date and time to the \# date and time encoded in a group of directory names. These directories

\# are named for the date and time of the event.

\# The dates and times in each of these may not be an exact match, so

\# cannot be done by direct comparison. Instead, we will calculate the

\# difference in seconds between the two timestamps, and declare a match

\# if the difference is below a tolerance threshold.

\# The first command-line parameter must be the name of the .PHA file to read.

\# The second command-line parameter must be the path to the collection of

\# waveform directories.

\# The third command-line parameter must be the match tolerance, in seconds.

\# Timestamps that differ by $<=$ this amount will be said to match.

import sys, subprocess

from datetime import date, time, datetime

prg_name $=$ sys.argv.pop $(0)$

if len( sys.argv ) != 3:

sys.exit( 'Incorrect number of parametersInUsage: ' + prg_name + ' <phaFile> <path to waveform directories $><$ seconds of tolerance $>$ ' )

phaFile $=$ sys.argv[0]

phaMatchFile = 'matched.pha'

phaNoMatchFile $=$ 'unmatched.pha'

wavePath $=$ sys.argv[1].rstrip('/')

waveGlob = '???????? ?????? ta' \# yyyymmdd hhmmss ta

wavePattern $=' \% \mathrm{Y} \% \mathrm{~m} \% \mathrm{~d} \_\% \mathrm{H} \% \mathrm{M} \% \mathrm{~S}$ ta' \# for parsing waveDir name to a date/time

phaPattern $=$ ' $\%$ Y\%m\%d $\% \mathrm{H} \% \mathrm{M} \% \mathrm{~S}^{\prime}$

tolerance $=$ int ( sys.argv[2] )

$f$ = open( phaFile, ' $r$ ' )

$\mathrm{mf}=$ open ( phaMatchFile, ' $w$ ' ) \# matched PHA data gets written here

uf = open ( phaNoMatchFile, ' ' $w$ ' ) \# unmatched PHA data gets written here

findCmd = "[ -d "' + wavePath + "'] \&\& cd "' + wavePath + "' \&\& find . -maxdepth 1 -mindepth 1 -

type d -name "' + waveGlob + "' | sed -e 's-^l./--"'

waveDirs = subprocess.check_output( findCmd, shell=True )

\#print findCmd

\#print type( waveDirs )

waveDirs $=$ waveDirs.splitlines ()

waveDirs.sort()

print '\# \%d waveform directories found at path \%s' \% ( len(waveDirs), wavePath )

\#while len( waveDirs ) > 0:

\# $\quad$ dir = waveDirs.pop(0)

\# print dir

\#sys.exit()

matched $=$ False

$\operatorname{dir}=$ None 
for line in $f$ :

\#print line,

phaVars = line.split()

if phaVars[0] == '\#':

matched $=$ False

pyr $=$ int $($ phaVars[1] $)$

pmo $=$ int $($ phaVars[2] $)$

pda $=\operatorname{int}($ phaVars[3] $)$

phr $=$ int $($ phaVars[4] $)$

pmi $=$ int $($ phaVars[5] $)$

pse $=$ phaVars $[6]$

pse = int( pse.split('.')[0] ); \# remove decimal fraction from seconds

pid = phaVars[ 14 ] \# unique ID number

$\mathrm{s}={ }^{\circ} \% 04 \mathrm{i} \% 02 \mathrm{i} \% 02 \mathrm{i} \% 02 \mathrm{i} \% 02 \mathrm{i} \% 02 \mathrm{i}$ ' \% ( pyr, pmo, pda, phr, pmi, pse )

print '\# pha: ', pid, $s$

pdt $=$ date $($ pyr, pmo, pda $)$

ptm $=$ time $($ phr, pmi, pse $)$

elif matched:

\#print pdt, ptm

mf.write( line ) \# output station lines if previous PHA matched

continue

else:

uf.write( line ) \# output unmatched station lines to unmatched file continue

$\operatorname{dir}=$ None

while dir $==$ None:

if len( waveDirs ) > 0:

$\operatorname{dir}=$ waveDirs.pop $(0)$

print '\# wav: ', dir

if $\operatorname{dir}==$ None:

print '\# wav: EOF'

\# Break out of this while loop, no more waveDirs to check break

waveDate $=$ datetime. strptime(dir, wavePattern)

\#print waveDate

phaDate = datetime.strptime(s, phaPattern)

$\mathrm{td}=$ phaDate - waveDate \# which create a timeDelta object

$\mathrm{td}=$ td.total_seconds ()

\#print td, tolerance

\#print type( td ), type( abs(td)), type( tolerance ), type( abs( td )<= tolerance )

\#if abs( td ) <= tolerance:

if $(\mathrm{td}>0)$ and $(\mathrm{td}<=$ tolerance):

\# yay! a match

\#print 'within tolerance'

print 'match pha: ', phaDate, ' wav: ', waveDate, ' delta: ', td, ' id: ', pid, dir matched $=$ True

else:

mf.write( line ) \# write the matched PHA to match file

if $t d>0$ : $\quad$ \# if phaDate $>$ waveDate

print '\# phaDate > waveDate, skip to next waveDate'

dir = None \# then try to compare against next waveDir

else:

print '\# waveDate > phaDate, no match for this phaDate' waveDirs.insert( 0 , dir) \# push dir back onto top of stack 
\# end while dir $==$ None

uf.write( line ) \# write the unmatched PHA to unmatched file

if $\mathrm{dir}==$ None:

matched $=$ False

print '\# no more waveDirs to check.'

print '\# no match for pha: ', phaDate, ' Terminating.'

uf.write( line ) \# write the unmatched PHA to unmatched file

\#break

continue

\#print 'Comparing:'

\#print '\#', phaDate

\#print 'W' ', waveDate

\#print 'D', td

\#dir = None

print phaVars[0]

\# end for line in $f$

f.close()

7.2.2 MATLAB script (SAC_add_pick_crscrl.m) created by Dr. Jackie Caplan-Auerbach

\%this uses .pha and evid_tempid.list to add traveltime and adjust header

$\%$ reference time to be the event origin time

CHECKDATA = 0;

$\%$ list all waveform directories

fid2 = fopen('evid_tempid.list');

tline2 = fgetl(fid2);

$\mathrm{k}=1$;

clear IDs DIRs

while $\mathrm{k}<2508$

IDs $(k)=$ str2num(tline2(2:9));

$\operatorname{DIRs}(\mathrm{k},:)=$ tline2(11:18);

tline $2=$ fgetl(fid2)

$\mathrm{k}=\mathrm{k}+1$;

end

fclose(fid2);

$\%$ open phase file and read data

fid = fopen('tanaga12-18. pha');

$\mathrm{GO}=1$

$\mathrm{i}=0$;

$\%$ read in data

tline = fgetl(fid);

while GO

$\%$ origin line starts with \#, so get origin data from that line

if strcmp(tline(1), '\#')

disp(tline)

evid = str2num(tline(79:end));

$\mathrm{i}=\mathrm{i}+1 ; \operatorname{disp}(\mathrm{i})$

YEAR = str2num(tline(3:6));

MONTH = str2num(tline(8:9));

DAY = str2num(tline $(11: 12))$;

HOUR = str2num(tline(14:15));

MINUTE = str2num(tline $(17: 18))$; 


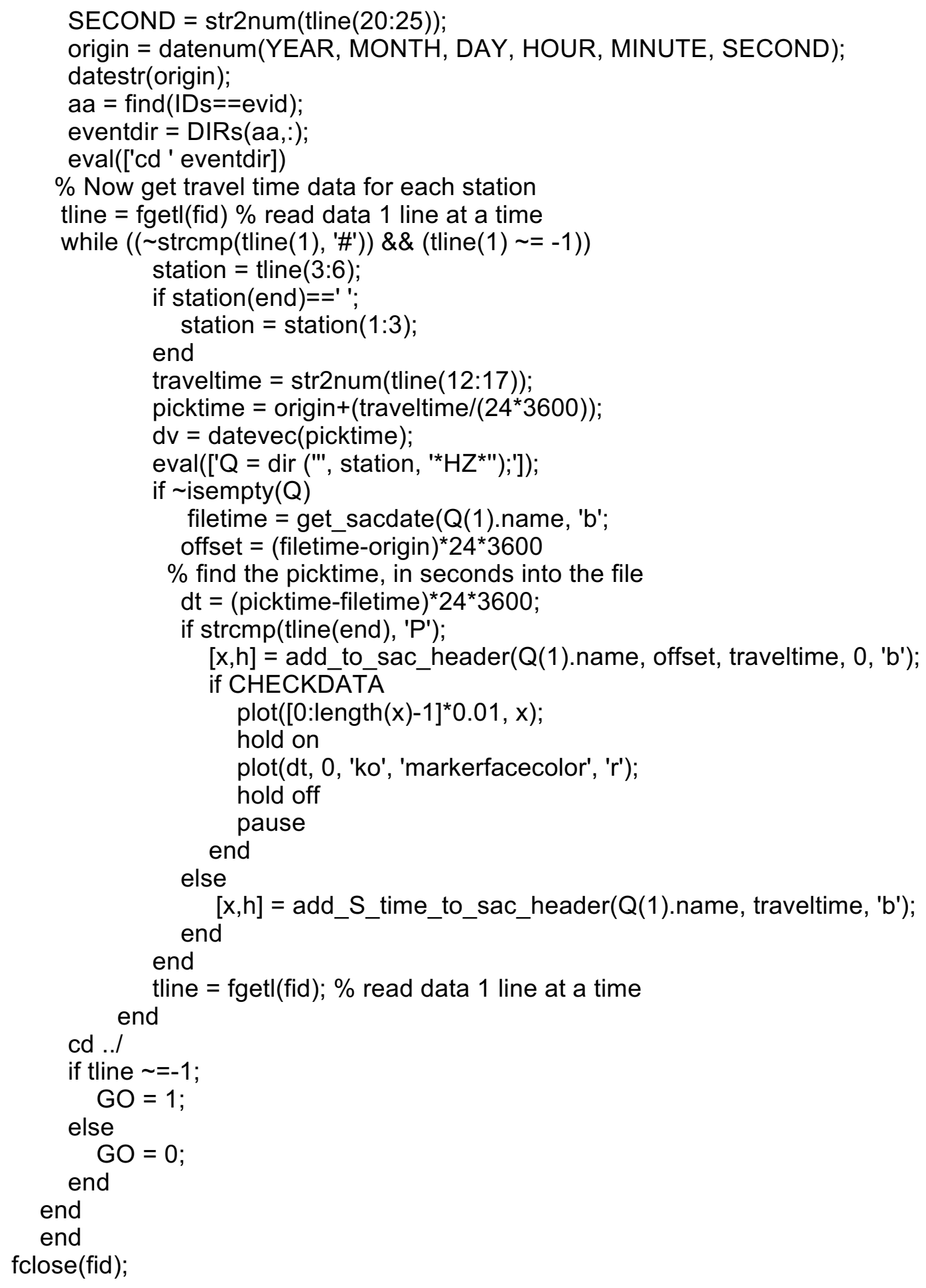


7.3 Map of original catalog locations (calculated by AVO)

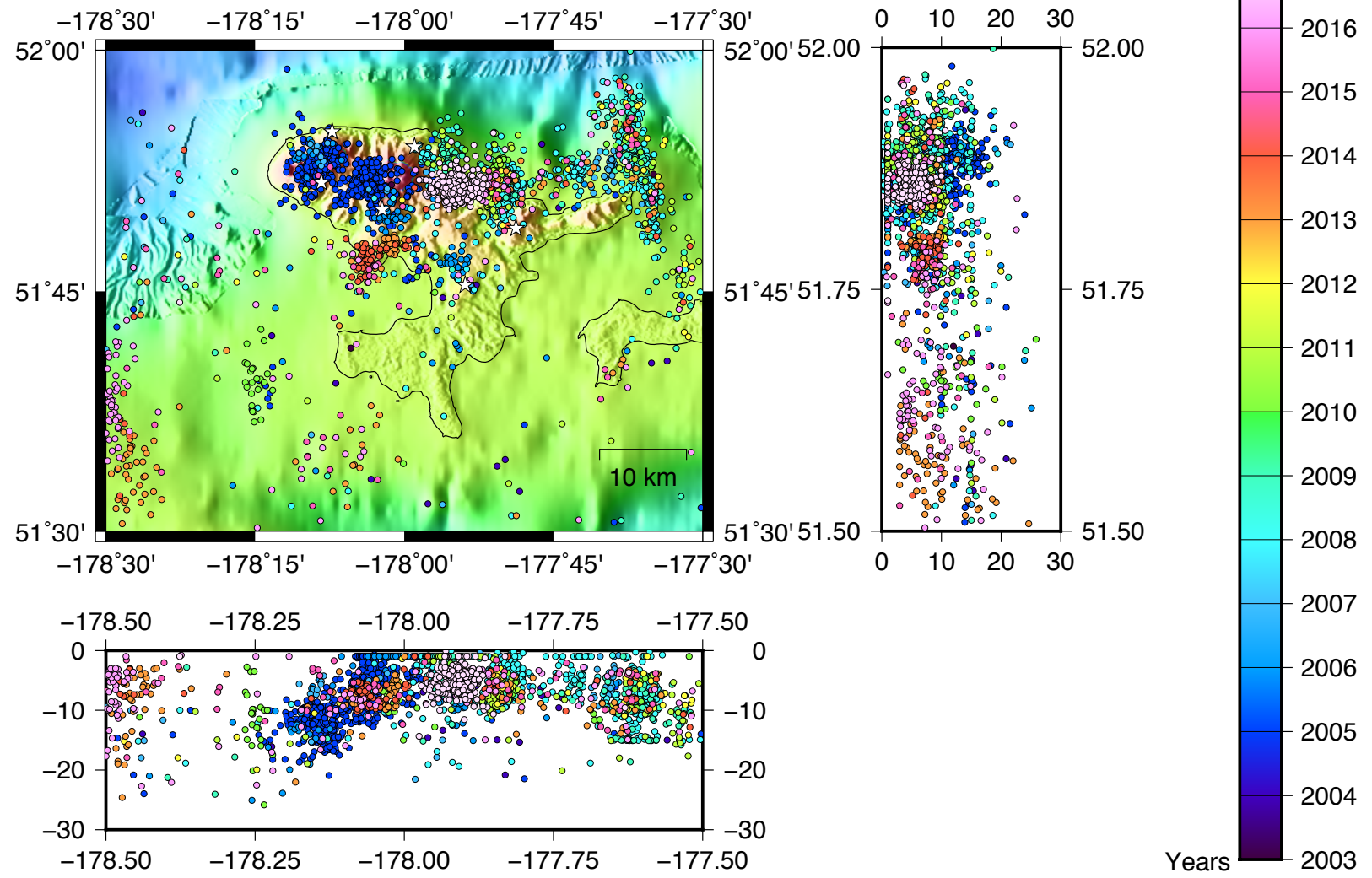

Figure 23: Map of Tanaga Island, Alaska displaying original catalog locations (colored circles) of seismicity between October 2003 - February 2017. White stars show seismic station locations. Depths (in km) of hypocenters within the map area are projected below and to the right of the map on a E-W plane (looking north), and on a N-S plane (looking west). Catalog locations courtesy of AVO.

\subsection{Catalog of HypoDD relocations}

Contact by email (Kevinfrancislally@gmail.com) for access to the complete catalog of HypoDD relocations. 